\title{
Computing gradient-based stepwise benchmarking paths
}

\author{
Sebastián Lozano ${ }^{\S a}$ and Laura Calzada-Infante ${ }^{\mathrm{b}}$ \\ ${ }^{a}$ Dept. of Industrial Management, University of Seville, Spain \\ ${ }^{\mathrm{b}}$ Engineering School, University of Oviedo, Spain
}

PAPER PUBLISHED IN OMEGA (2018)

https://doi.org/10.1016/j.omega.2017.11.002

\begin{abstract}
In this paper, a new stepwise benchmarking approach is presented. It is based on the concept of efficiency field potential given by a continuous and differentiable function that decreases monotonously as the amount of inputs consumed is reduced and the amount of outputs produced is increased. A gradient-based stepwise efficiency improvement method is proposed and the graphical interpretation of the continuous gradient-based trajectories is shown. A minimum potential DEA model is also formulated. The proposed approach is units invariant and can take into account preference structure, non-discretionary variables and undesirable outputs. The proposed method has been applied to an organic farming dataset.
\end{abstract}

Keywords: Data Envelopment Analysis (DEA); stepwise benchmarking; efficiency field potential; efficiency field vector; organic farming

\section{Introduction}

Data Envelopment Analysis (DEA) is a well-known non-parametric methodology for assessing the relative efficiency of a set of Decision Making Units (DMUs). From the inputs consumption and outputs production of the observed DMUs, and using a few axioms such as convexity and free disposability, DEA infers a Production Possibility Set (PPS) (a.k.a. DEA technology) which contains all the feasible operating points. The corresponding nondominated subset is the Efficient Frontier (EF). Conventional DEA models project the inefficient DMUs on the EF using an orientation (input, output, directional distance, etc.) and a metric (radial, non-radial, slacks-based, etc.) (see, e.g., Zhu 2002, Cooper et al. 2004, 2007).

$\S$ Corresponding author:

Escuela Superior de Ingenieros

Camino de los Descubrimientos, s/n, 41092 Sevilla, Spain

(Phone: +34-954487208 E-mail: slozano@us.es) 
Note, however, that some DEA models (like radial, directional distance, hyperbolic, etc) do not necessarily exhaust all input and output slacks and hence may compute targets that are only weakly efficient.

Since conventional DEA models aim at reducing inputs and/or increasing outputs as much as possible, they tend to compute efficient targets that are as "far" from the observed DMU as possible. This makes those targets harder to achieve since the improvements in terms of the corresponding input reductions and output increases may be significant.

One way to alleviate this distant target problem is to compute the closest efficient targets. There is an abundant literature on the subject, dating back to Frei and Harker (1999), which used the Euclidean distance to the strongly efficient frontier. A weighted Euclidean distance to the strongly efficient frontier has been used by Baek and Lee (2009), Amirteimoori and Kordrostami (2010) and Aparicio and Pastor (2014a). Other authors have used other ways of measurement the similarity/closeness between the DMU and the potential efficient targets (e.g. Cherchye and Van Puyenbroeck 2001, Silva Portela et al. 2003). Other approaches include Gonzalez and Alvarez (2001), which propose a modified version of the input-oriented Russell efficiency measure, and Aparicio et al. (2007), which use an Enhanced Russell Graph Measure (ERGM, a.k.a. Slacks-Based Measure, SBM) together with a characterization of the Pareto-efficient frontier based on the set of extreme efficient DMUs. Additional papers dealing with least distance target computation are Pastor and Aparicio (2010), Ando et al. (2012, 2017), Aparicio and Pastor (2013, 2014b) and Aparicio et al. (2014). The reader is referred to Aparicio (2016) and Aparicio et al. (2017a, 2017b) for recent developments in the field as well as an up-to-date review of the literature on this topic.

Another line of research, which is the one followed in this paper, is to compute a stepwise improvement path so that a number of Intermediate Benchmark targets (IBTs) are computed, leading to an Ultimate Benchmark target (UBT) on the EF. There are two types of stepwise efficiency improvement method: those that use the existing DMUs as IBT and UBT and those that compute IBT and UBT belonging to the PPS and EF respectively, but not necessarily coincident with any of the existing DMUs. The second group is composed of just a few approaches, basically Lozano and Villa (2005, 2010), Suzuki and Nijkamp (2011), Khodakarami et al. (2014) and Fang (2015). The first group is more numerous and, in most cases, uses the stratification approach proposed in the Context-Dependent (CD) DEA approach of Seiford and Zhu (2003) which identifies successive layers of DMUs and computes so-called attractiveness and progress measures for each DMU with respect to the different DMU layers. 
Table 1 shows a summary of the main characteristics of the different approaches. In particular, for each approach the table shows the type of IBT and UBT considered, whether stratification is used, whether the benchmarking path is computed over a benchmark network (whose nodes are the DMUs and whose edges indicate the possible steps that can be taken to form the efficiency improvement path), whether bounds on the stepsizes are considered, whether the DMUs are clustered, the similarity criteria considered for selecting each IBT and whether the method suffers from zigzagging (i.e. moving in inverse directions in successive steps). The final column shows some specific features of the methods.

\section{Table 1}

Note that most methods have used stratification to segment the sample and clustering to group similar DMUs based mainly on their inputs (although sometimes on inputs and outputs or on cross-efficiency scores). Self-Organizing Maps (SOMs) and k-means are the clustering algorithms generally used. Those methods that consider only the existing DMUs use clustering and other mechanisms (such as directional similarity) to try to compute consistent benchmarking paths (so that if an input is reduced in one step it is not increased in the next) but in general they cannot prevent zigzagging from happening.

Note that some (but not all) methods limit the amount of inputs and outputs changes allowed in each step. Those methods that build a benchmark network usually compute the sequence of targets solving a shortest path problem. In order to select the next IBT along the benchmarking path, different criteria have been considered. Thus, they can be required to belong to the same cluster as the original DMU being projected or they should not be far (in terms of the inter-cluster distance or in terms of SOM distance) from the previous IBT. Using the attractiveness and progress measures computed by the CD, DEA stratification has also been proposed. The distance between the current IBT and the candidates for the next IBT is often taken into account as it is also the change in efficiency between those DMUs.

Among the specific features of some of the methods, we have the possibility of using a preference structure to select the UBT, the consideration of a fixed cost for carrying out each benchmarking step or computing a decision tree from the DMU stratification to try to identify the differences in inputs and output ranges in two successive layers. The extension of stepwise benchmarking to centralized DEA and to systems with two stages in series is also remarkable. 
In this paper, a completely new stepwise benchmarking approach that uses the gradient of an efficiency field potential (EFP) is presented. Thus, each feasible operating point is assigned a scalar EFP so that the negative gradient of that potential defines an efficiency field vector (EFV). The proposed stepwise efficiency improvement path is computed by moving a discrete stepsize along the direction of this EFV. Since the negative gradient of the EFP always points to the less-input/more-output subspace, a step in that direction monotonously reduces the inputs and increases the outputs so that after a finite number of steps an EF target is reached. The continuous version of the method corresponds to moving along the efficiency field lines perpendicular to the efficiency equipotential surfaces and defines rather interesting trajectories, which can be easily visualized in the case of a single input as well as in the case of two inputs and a constant output or two outputs and a constant input. The proposed approach is units invariant and can accommodate a preference structure as well as non-discretionary variables and undesirable outputs.

The EFP and EFV concepts introduced in this paper are original contributions. The closest relatives we have found in the DEA literature are the Geometric Distance Function (GDF) used in, for example, Silva Portela and Thanassoulis (2007), the dominance network profit potential in Lozano and Calzada-Infante (2017) and the two-dimensional gradient line approach in Maital and Vaninsky (1999). The proposed approach is, however, completely different, differing from such approaches in its purpose and in the methodology and concepts used. Thus, Silva Portela and Thanassoulis (2007) use GDF mainly as way of measuring technical efficiency. i.e. measuring the distance from an observed DMU to its target. Although the functional form of GDF is also multiplicative, they use geometric averages and they neither define a potential function on the PPS as this paper does, nor do they study stepwise efficiency improvements. On the other hand, Lozano and Calzada-Infante (2017) use the concept of profit potential to designate the profit associated to each operating point. They do that in the context of a dominance network where the nodes represent the DMU and the arcs go from lower profit nodes to larger profit nodes. Those dominance networks are then studied using complex network analysis tools. Finally, Maital and Vaninsky (1999) compute so-called gradient lines on a two-dimensional section of the PPS determined by a simultaneous radial input reduction and radial output expansion. With their approach they are able to determine locally optimal proportional change in inputs and outputs using the information provided by a single DMU.

The structure of the paper is the following. In Section 2 the efficiency field potential, efficiency equipotential surface, efficiency field vector and gradient-based trajectories are 
presented. In Section 3 the proposed gradient-based stepwise benchmarking approach is formulated and illustrated on a simple two-dimensional dataset. Section 4 presents some extensions of the proposed approach. Section 5 presents an application of the proposed approach while Section 6 summarizes and concludes.

\section{Efficiency field potential and efficiency field vector}

Let us consider that we have a set of $n$ DMUs which consume $m$ inputs and produce $s$ outputs. Let $\mathrm{I}$ and $\mathrm{O}$ represent the set of inputs and outputs, respectively. Let $\mathrm{x}_{\mathrm{j}}=\left(\mathrm{x}_{1 \mathrm{j}}, \mathrm{x}_{2 \mathrm{j}}, \ldots \mathrm{x}_{\mathrm{mj}}\right)$ and $\mathrm{y}_{\mathrm{j}}=\left(\mathrm{y}_{1 \mathrm{j}}, \mathrm{y}_{2 \mathrm{j}}, \ldots \mathrm{y}_{\mathrm{sj}}\right)$ the input and output vectors, respectively, of DMU j. Using the conventional DEA methodology, the following Variable Returns to Scale (VRS) PPS can be inferred from the observations

$$
\mathrm{T}^{\mathrm{VRS}}=\left\{(\mathrm{x}, \mathrm{y}) \in \Pi^{\mathrm{m}+\mathrm{s}}: \exists \lambda_{\mathrm{j}} \geq 0 \sum_{\mathrm{j}=1}^{\mathrm{n}} \lambda_{\mathrm{j}}=1 \sum_{\mathrm{j}=1}^{\mathrm{n}} \lambda_{\mathrm{j}} \mathrm{x}_{\mathrm{ij}} \leq \mathrm{x}_{\mathrm{i}} \forall \mathrm{i} \sum_{\mathrm{j}=1}^{\mathrm{n}} \lambda_{\mathrm{j}} \mathrm{y}_{\mathrm{kj}} \geq \mathrm{y}_{\mathrm{k}} \forall \mathrm{k}\right\}
$$

Using the average of the different input and output dimensions $\mathrm{x}_{\mathrm{i}}^{\text {aver }}$ and $\mathrm{y}_{\mathrm{k}}^{\mathrm{aver}}$ appropriate dimensionless inputs and output vector for the observed DMUs can be computed

$$
\hat{\mathrm{x}}_{\mathrm{ij}}=\frac{\mathrm{x}_{\mathrm{ij}}}{\mathrm{x}_{\mathrm{i}}^{\mathrm{aver}}} \forall \mathrm{i} \forall \mathrm{j} \quad \hat{\mathrm{y}}_{\mathrm{kj}}=\frac{\mathrm{y}_{\mathrm{kj}}}{\mathrm{y}_{\mathrm{k}}^{\text {aver }}} \forall \mathrm{k} \forall \mathrm{j}
$$

There is a one to one correspondence between the VRS PPS $\mathrm{T}^{\mathrm{VRS}}$ and the corresponding VRS PPS defined using the dimensionless input and output vectors

$$
\hat{\mathrm{T}}^{\mathrm{VRS}}=\left\{(\hat{\mathrm{x}}, \hat{\mathrm{y}}) \in \square^{\mathrm{m}+\mathrm{s}}: \exists \lambda_{\mathrm{j}} \geq 0 \sum_{\mathrm{j}=1}^{\mathrm{n}} \lambda_{\mathrm{j}}=1 \sum_{\mathrm{j}=1}^{\mathrm{n}} \lambda_{\mathrm{j}} \hat{\mathrm{x}}_{\mathrm{ij}} \leq \hat{\mathrm{x}}_{\mathrm{i}} \forall \mathrm{i} \sum_{\mathrm{j}=1}^{\mathrm{n}} \lambda_{\mathrm{j}} \hat{\mathrm{y}}_{\mathrm{kj}} \geq \hat{\mathrm{y}}_{\mathrm{k}} \forall \mathrm{k}\right\}
$$

Thus, if $\hat{x}_{\mathrm{i}}=\frac{\mathrm{x}_{\mathrm{i}}}{\mathrm{x}_{\mathrm{i}}^{\text {aver }}} \forall \mathrm{i} \quad \hat{\mathrm{y}}_{\mathrm{k}}=\frac{\mathrm{y}_{\mathrm{k}}}{\mathrm{y}_{\mathrm{k}}^{\text {aver }}} \forall \mathrm{k}$ then $(\mathrm{x}, \mathrm{y}) \in \mathrm{T}^{\mathrm{VRS}} \Leftrightarrow(\hat{\mathrm{x}}, \hat{\mathrm{y}}) \in \hat{\mathrm{T}}^{\mathrm{VRS}}$.

For each feasible operating point $(\hat{x}, \hat{y})$ with $\hat{x}>0$ and $\hat{y}>0$ we can assign the following strictly positive EFP

$$
\mathrm{P}(\hat{\mathrm{x}}, \hat{\mathrm{y}})=\frac{\prod_{\mathrm{i}=1}^{\mathrm{m}} \hat{\mathrm{x}}_{\mathrm{i}}}{\prod_{\mathrm{k}=1}^{\mathrm{s}} \hat{\mathrm{y}}_{\mathrm{k}}}
$$


It is clear that the less input an operating point consumes and the more output it produces, the lower its EFP. Note also that, since the dimensionless input and output vectors of the average DMU have all components equal to one, its associated EFP is also one, i.e. $\mathrm{P}\left(\hat{\mathrm{x}}^{\text {aver }}, \hat{\mathrm{y}}^{\text {aver }}\right)=\mathrm{P}(\mathbf{1}, \mathbf{1})=1$. In spite of these and other interesting features that will be commented below, it must be acknowledged the above definition of the EFP is somewhat arbitrary. As it has been discussed in the literature (e.g. Ebert and Welsch 2004, Cherchye et al. 2007) other functional forms as well as other ways of normalizing the variables and removing their dimensions can be devised, with the different alternatives having different properties as regards invariance, strong/weak monotonicity, separability, etc. Hence, although the proposed approach uses the EFP definition given in (4), in principle it may be adapted to work also with other alternative EFP specifications. The resulting efficiency improvement path for other EFP specifications would of course be different, but its main properties (i.e. strong monotonicity and efficiency achievement) can be maintained.

The Efficiency Equipotential Surfaces (EESs) correspond to

$$
\frac{\prod_{\mathrm{i}=1}^{\mathrm{m}} \hat{\mathrm{x}}_{\mathrm{i}}}{\prod_{\mathrm{k}=1}^{\mathrm{s}} \hat{\mathrm{y}}_{\mathrm{k}}}=\gamma \Leftrightarrow \prod_{\mathrm{k}=1}^{\mathrm{s}} \hat{\mathrm{y}}_{\mathrm{k}}=\gamma^{-1} \prod_{\mathrm{i}=1}^{\mathrm{m}} \hat{\mathrm{x}}_{\mathrm{i}}
$$

More importantly, the EFP has an associated EFV given by the negative EFP gradient

$$
\mathrm{E}(\hat{\mathrm{x}}, \hat{\mathrm{y}})=-\nabla \mathrm{P}(\hat{\mathrm{x}}, \hat{\mathrm{y}})=\left(-\frac{\partial \mathrm{P}}{\partial \hat{\mathrm{x}}_{1}},-\frac{\partial \mathrm{P}}{\partial \hat{\mathrm{x}}_{2}}, \ldots,-\frac{\partial \mathrm{P}}{\partial \hat{\mathrm{x}}_{\mathrm{m}}},-\frac{\partial \mathrm{P}}{\partial \hat{\mathrm{y}}_{1}},-\frac{\partial \mathrm{P}}{\partial \hat{\mathrm{y}}_{2}}, \ldots,-\frac{\partial \mathrm{P}}{\partial \hat{\mathrm{y}}_{\mathrm{s}}}\right)
$$

The corresponding partial derivatives can be easily computed and, interestingly, can be expressed in terms of the EFP since

$$
\frac{\partial \mathrm{P}}{\partial \hat{\mathrm{x}}_{\mathrm{i}}}=\frac{\prod_{\mathrm{i}^{\prime} \neq \mathrm{i}} \hat{\mathrm{x}}_{\mathrm{i}^{\prime}}}{\prod_{\mathrm{k}} \hat{\mathrm{y}}_{\mathrm{k}}}=\frac{\mathrm{P}(\hat{\mathrm{x}}, \hat{\mathrm{y}})}{\hat{\mathrm{x}}_{\mathrm{i}}} \quad \forall \mathrm{i} \quad \frac{\partial \mathrm{P}}{\partial \hat{\mathrm{y}}_{\mathrm{k}}}=-\frac{1}{\hat{\mathrm{y}}_{\mathrm{k}}^{2}} \frac{\prod_{\mathrm{i}} \hat{\mathrm{x}}_{\mathrm{i}}}{\prod_{\mathrm{k}^{\prime} \neq \mathrm{k}} \hat{\mathrm{y}}_{\mathrm{k}^{\prime}}}=-\frac{\mathrm{P}(\hat{\mathrm{x}}, \hat{\mathrm{y}})}{\hat{\mathrm{y}}_{\mathrm{k}}} \quad \forall \mathrm{k}
$$

Note that the components of the EFV

$$
E(\hat{x}, \hat{y})=\left(-\frac{P(\hat{x}, \hat{y})}{\hat{x}_{1}},-\frac{P(\hat{x}, \hat{y})}{\hat{x}_{2}}, \ldots,-\frac{P(\hat{x}, \hat{y})}{\hat{x}_{m}}, \frac{P(\hat{x}, \hat{y})}{\hat{y}_{1}}, \frac{P(\hat{x}, \hat{y})}{\hat{y}_{2}}, \ldots, \frac{P(\hat{x}, \hat{y})}{\hat{y}_{s}}\right)
$$


always point towards the less input/more output region. It is also clear that at each feasible operating point $(\hat{x}, \hat{y}), E(\hat{x}, \hat{y})$ is perpendicular to the corresponding EES. Figure 1 shows the EFV for three special cases that can be shown in a bidimensional plot. These three cases correspond to a single input and a single output (case XY), two inputs and a constant output (case XX1) and two outputs and constant input (case 1YY).

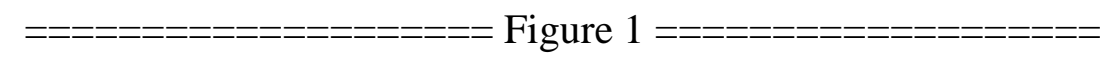

In the XY case, the EESs are straight lines that pass through the origin. The Efficiency Field Lines (EFLs), which are tangent to the EFV (and hence perpendicular to the EES), correspond to circles centred at the origin.

In the XX1 case the EESs are rectangular hyperboles whose EP decreases as they approach the origin. The corresponding EFLs are also hyperboles which are symmetrical around the bisector line $\hat{\mathrm{x}}_{1}=\hat{\mathrm{x}}_{2}$. The case $1 \mathrm{YY}$ is similar, with the only difference being that the EFP of the EES decreases as the hyperboles move away from the origin.

The mathematical expressions for the EFL correspond to the following differential equation, which represents moving along the direction of the negative EFP gradient

$$
\left(\frac{\mathrm{d} \hat{x}}{\mathrm{dt}}, \frac{\mathrm{d} \hat{y}}{\mathrm{dt}}\right)=-\nabla \mathrm{P}(\hat{\mathrm{x}}, \hat{\mathrm{y}})
$$

Solving this partial differential equation with boundary condition $\left(\hat{\mathrm{x}}_{0}, \hat{\mathrm{y}}_{0}\right)$ leads to the following three groups of quadratic surfaces

$$
\begin{aligned}
& \hat{\mathrm{x}}_{\mathrm{i}}^{2}-\hat{\mathrm{x}}_{\mathrm{i}^{\prime}}^{2}=\hat{\mathrm{x}}_{\mathrm{i} 0}^{2}-\hat{\mathrm{x}}_{\mathrm{i}^{\prime} 0}^{2} \quad \forall \mathrm{i} \neq \mathrm{i}^{\prime} \\
& \hat{\mathrm{y}}_{\mathrm{k}}^{2}-\hat{\mathrm{y}}_{\mathrm{k}^{\prime}}^{2}=\hat{\mathrm{y}}_{\mathrm{k} 0}^{2}-\hat{\mathrm{y}}_{\mathrm{k}^{\prime} 0}^{2} \quad \forall \mathrm{k} \neq \mathrm{k}^{\prime} \\
& \hat{\mathrm{x}}_{\mathrm{i}}^{2}+\hat{\mathrm{y}}_{\mathrm{k}}^{2}=\hat{\mathrm{x}}_{\mathrm{i} 0}^{2}+\hat{\mathrm{y}}_{\mathrm{k} 0}^{2} \quad \forall \mathrm{i}, \mathrm{k}
\end{aligned}
$$

Of the first group of $\mathrm{m} \cdot(\mathrm{m}-1) / 2$ equations in (10), only $\mathrm{m}-1$ are linearly independent. Similarly, only s-1 equations out of the $s \cdot(s-1) / 2$ equations in the second group are linearly independent. And only 1 equation from the third group is linearly independent. This means that the total number of linearly independent equations is $\mathrm{m}+\mathrm{s}-1$ which means that (10) defines a one-dimensional subspace. The EFLs are curves that result from the intersection of this equation system. Thus, for example, in the XY case seen above, (10) reduces to 
$\hat{\mathrm{x}}^{2}+\hat{\mathrm{y}}^{2}=\hat{\mathrm{x}}_{0}^{2}+\hat{\mathrm{y}}_{0}^{2}$

which corresponds to the circular EFLs that can be noticed in panel a) of Figure 1. Similarly, in the XX1 case the EFLs (10) reduce to

$\hat{\mathrm{x}}_{1}^{2}-\hat{\mathrm{x}}_{2}^{2}=\hat{\mathrm{x}}_{10}^{2}-\hat{\mathrm{x}}_{20}^{2}$

which for $\hat{\mathrm{x}}_{10} \neq \hat{\mathrm{x}}_{20}$ are hyperboles and for $\hat{\mathrm{x}}_{10}=\hat{\mathrm{x}}_{20}$ corresponds to the bisector line $\hat{\mathrm{x}}_{1}=\hat{\mathrm{x}}_{2}$. Finally, in the $1 \mathrm{YY}$ case, the EFLs (10) reduce to

$\hat{\mathrm{y}}_{1}^{2}-\hat{\mathrm{y}}_{2}^{2}=\hat{\mathrm{y}}_{10}^{2}-\hat{\mathrm{y}}_{20}^{2}$

which, again, are hyperboles for $\hat{y}_{10} \neq \hat{y}_{20}$ and the bisector line $\hat{y}_{1}=\hat{y}_{2}$ if $\hat{y}_{10}=\hat{y}_{20}$.

\section{Proposed gradient-based stepwise benchmarking approach}

\subsection{Stepwise efficiency improvement path}

As shown in the previous section, the EFV always points towards less input and more output. Following such direction leads to a strictly increasing efficiency. The trajectories defined by the EFL (10) correspond to the continuous path that results from following the EFV as per (9). However, changing the inputs in a continuous fashion is not practical and may not even be implementable. That is why we propose a stepwise benchmarking approach which is a discrete version of that continuous efficiency improvement trajectory.

Assume that a stepwise efficiency improvement path from DMU 0 is to be computed. DMU 0 will the starting point, i.e. the step $\mathrm{t}=0$, of efficiency improvement path $\left(\hat{\mathrm{x}}^{0}, \hat{\mathrm{y}}^{0}\right)=\left(\hat{\mathrm{x}}_{0}, \hat{\mathrm{y}}_{0}\right)$. Assuming that $\hat{\mathrm{x}}^{\mathrm{t}}>0$ and $\hat{\mathrm{y}}^{\mathrm{t}}>0$, the corresponding EFP and EFV $\mathrm{P}\left(\hat{\mathrm{x}}^{\mathrm{t}}, \hat{\mathrm{y}}^{\mathrm{t}}\right)$ and $\mathrm{E}\left(\hat{\mathrm{x}}^{\mathrm{t}}, \hat{\mathrm{y}}^{\mathrm{t}}\right)$, respectively, can easily be computed. In each iteration two DEA models are solved. The first one is labelled the Improvement Dimensions (ID) DEA model and determines the input and output dimensions that can be improved in that step. Let

Data

$\left(\hat{\mathrm{x}}^{\mathrm{t}}, \hat{\mathrm{y}}^{\mathrm{t}}\right) \quad$ Current (i.e. step t) IBT

$\mathrm{E}\left(\hat{\mathrm{x}}^{\mathrm{t}}, \hat{\mathrm{y}}^{\mathrm{t}}\right) \quad$ EFV at current IBT 
$\varepsilon \quad$ Small value stepsize along EFV from current IBT

\section{Decision variables}

$\lambda_{\mathrm{j}} \quad$ linear combination variables used to compute a feasible operating point

$\mathrm{u}_{\mathrm{i}} \quad$ binary variable indicating whether input dimension $\mathrm{i}$ can be improved moving in the EFV direction

$\mathrm{v}_{\mathrm{k}} \quad$ binary variable indicating whether output dimension $\mathrm{k}$ can be improved moving in the EFV direction

\section{$\underline{\text { ID DEA model (iteration } \mathrm{t} \text { ) }}$}

$\operatorname{Max} \sum_{\mathrm{i}=1}^{\mathrm{m}} \mathrm{u}_{\mathrm{i}}+\sum_{\mathrm{k}=1}^{\mathrm{s}} \mathrm{v}_{\mathrm{k}}$

s.t.

$\sum_{j=1}^{n} \lambda_{j} \hat{x}_{i j} \leq \hat{x}_{i}^{t}+\varepsilon \cdot \frac{E_{i}\left(\hat{x}^{t}, \hat{y}^{t}\right)}{\left\|E\left(\hat{x}^{t}, \hat{y}^{t}\right)\right\|} \cdot u_{i} \quad \forall i$

$\sum_{j=1}^{n} \lambda_{j} \hat{y}_{k j} \geq \hat{y}_{k}^{t}+\varepsilon \cdot \frac{E_{k}\left(\hat{x}^{t}, \hat{y}^{t}\right)}{\left\|E\left(\hat{x}^{t}, \hat{y}^{t}\right)\right\|} \cdot v_{k} \quad \forall k$

$\sum_{j=1}^{n} \lambda_{j}=1$

$\lambda_{\mathrm{j}} \geq 0 \quad \mathrm{j}=1,2, \ldots, \mathrm{n} \quad \mathrm{u}_{\mathrm{i}} \in\{0,1\} \forall \mathrm{i} \quad \mathrm{v}_{\mathrm{k}} \in\{0,1\} \forall \mathrm{k}$

This easy-to-solve Mixed Integer Linear Programming (MILP) model identifies all the input and output dimensions that can be improved in step $t$ along the EFV direction. Note that the above model is feasible. Thus, the current IBT $\left(\hat{\mathrm{x}}^{\mathrm{t}}, \hat{\mathrm{y}}^{\mathrm{t}}\right)$ corresponds to a feasible solution with $\mathrm{u}_{\mathrm{i}}=0 \forall \mathrm{i} \quad \mathrm{v}_{\mathrm{k}}=0 \forall \mathrm{k}$. The model is also bounded as it is the sum of a finite number of binary variables.

As regards parameter $\varepsilon$, its purpose is to detect whether we have reached the efficient frontier and, if not, which input and output dimensions can be improved. The stepwise benchmarking path computed does not depend on the exact value chosen, provided it is small enough. In principle, assuming that the current intermediate benchmark target (IBT) is not too 
close to the weak efficiency frontier any small positive value amount $\varepsilon>0$ can be used. Only if the IBT is very close to the weak efficiency frontier, i.e. one or more inputs or amounts may improve but just by a very small amount, precaution has to be taken to choose $\varepsilon$ small enough to detect that improvement in those dimensions is possible. Using a value equal to the precision level of the most precise of the input and output variables should be safe as, in that case, even if the possibility of improving a certain input or output dimension would go undetected, the magnitude of such improvement would be negligible and, for all practical purposes, the weak efficiency frontier had been reached. For example, if the border of the PPS along a certain output dimension corresponds to a value of 10.0 and the current IBT has reached a value very close to that, let us say 9.9, then the question is how to be able to detect that there is still a small margin to continue improving that output. Let us assume that the precision with which that variable is measured (in the observed data) is 0.1, i.e. one decimal position. If $\varepsilon>0.1$ then the model would not detect that this output dimension can be improved because there is no feasible operating point with an output equal to $9.9+\varepsilon>10.0$. Hence it should be $\varepsilon \leq 0.1$. If, instead, the output precision of the variable were two decimal positions and the current IBT had an output value of 9.92 then $\varepsilon=0.1$ would not detect that there is still some small margin for improvement as $9.92+\varepsilon>10.00$ would get us out of the PPS. In this second case it would have to be $\varepsilon \leq 0.01$ if we want to detect potential improvements of that size. In the above reasoning we have not taken into account the fact that in the ID DEA model (14)-(18) $\varepsilon$ multiplies the size of the normalized gradient component, which is lower than one, which means that a value of $\varepsilon$ somewhat larger than the precision value could be used, but it is better to be on the safe side and that is why we suggest $\varepsilon$ equal to the precision level. Note that, in any case, the value of $\varepsilon$ can be an issue only if the IBT is very close to the border of the PPS, something which occurs infrequently. Much more frequent is that the IBT exactly reaches the border of the PPS in a given step.

Given the optimal solution of the above model, the improvement dimensions sets $\mathrm{I}_{\mathrm{t}}^{-}$ and $\mathrm{O}_{\mathrm{t}}^{+}$can be determined as follows

$$
\mathrm{I}_{\mathrm{t}}^{-}=\left\{\mathrm{i}: \mathrm{u}_{\mathrm{i}}=1\right\} \quad \mathrm{O}_{\mathrm{t}}^{+}=\left\{\mathrm{k}: \mathrm{v}_{\mathrm{k}}=1\right\}
$$

If $\mathrm{I}_{\mathrm{t}}^{-}=\mathrm{O}_{\mathrm{t}}^{+}=\varnothing$, then $\left(\hat{\mathrm{x}}^{\mathrm{t}}, \hat{\mathrm{y}}^{\mathrm{t}}\right)$ is technically efficient and therefore there is no need to solve the corresponding gradient stepsize (GSS) DEA model. Otherwise, we would solve a GSS DEA model that computes the next IBT along the negative gradient direction. To control the stepsize, the unit vector in the direction pointed by the EFV is used. The model follows the 
negative EFP gradient direction and, if advancing the given stepsize $\Delta$ is feasible, then that would be the next IBT. Otherwise, the model advances as much as possible. Let

\section{Data}

$\mathrm{I}_{\mathrm{t}}^{-} \quad$ Input dimensions that can be improved in step $\mathrm{t}$

$\mathrm{O}_{\mathrm{t}}^{+} \quad$ Output dimensions that can be improved in step $\mathrm{t}$

$\left(\hat{\mathrm{x}}^{\mathrm{t}}, \hat{\mathrm{y}}^{\mathrm{t}}\right) \quad$ Current (i.e. step t) IBT

$\mathrm{E}\left(\hat{\mathrm{x}}^{\mathrm{t}}, \hat{\mathrm{y}}^{\mathrm{t}}\right) \quad \mathrm{EFV}$ at current IBT

\section{$\Delta \quad$ Desired stepsize value}

\section{Decision variables}

$\lambda_{\mathrm{j}} \quad$ linear combination variables used to compute a feasible operating point

$\left(\hat{x}^{t+1}, \hat{y}^{t+1}\right) \quad$ Next (i.e. step $\left.t+1\right)$ IBT

$\delta \quad$ Computed stepsize value

$\delta^{-}, \delta^{+}$Negative and positive deviations, respectively, from the desired stepsize value

\section{$\underline{\text { GSS DEA model (iteration } \mathrm{t} \text { ) }}$}

$\operatorname{Min} \delta^{-}+\delta^{+}$

s.t.

$$
\begin{aligned}
& \sum_{j=1}^{n} \lambda_{j} \hat{x}_{i j} \leq \hat{x}_{i}^{t+1}=\hat{x}_{i}^{t}+\delta \cdot \frac{E_{i}\left(\hat{x}^{t}, \hat{y}^{t}\right)}{\left\|E\left(\hat{x}^{t}, \hat{y}^{t}\right)\right\|} \quad \forall i \in I_{t}^{-} \\
& \sum_{j=1}^{n} \lambda_{j} \hat{x}_{i j} \leq \hat{x}_{i}^{t+1}=\hat{x}_{i}^{t} \quad \forall i \notin I_{t}^{-} \\
& \sum_{j=1}^{n} \lambda_{j} \hat{y}_{k j} \geq \hat{y}_{k}^{t+1}=\hat{y}_{k}^{t}+\delta \cdot \frac{E_{k}\left(\hat{x}^{t}, \hat{y}^{t}\right)}{\left\|E\left(\hat{x}^{t}, \hat{y}^{t}\right)\right\|} \quad \forall k \in O_{t}^{+}
\end{aligned}
$$




$$
\begin{aligned}
& \sum_{\mathrm{j}=1}^{\mathrm{n}} \lambda_{\mathrm{j}} \hat{\mathrm{y}}_{\mathrm{kj}} \geq \hat{\mathrm{y}}_{\mathrm{k}}^{\mathrm{t}+1}=\hat{\mathrm{y}}_{\mathrm{k}}^{\mathrm{t}} \quad \forall \mathrm{k} \notin \mathrm{O}_{\mathrm{t}}^{+} \\
& \sum_{\mathrm{j}=1}^{\mathrm{n}} \lambda_{\mathrm{j}}=1 \\
& \delta+\delta^{-}-\delta^{+}=\Delta \\
& \lambda_{\mathrm{j}} \geq 0 \quad \mathrm{j}=1,2, \ldots, \mathrm{n} \quad \delta \geq 0 \quad \delta^{-} \geq 0 \quad \delta^{+} \geq 0
\end{aligned}
$$

This linear programming (LP) model moves along the direction of the unit EFV $\frac{\mathrm{E}\left(\hat{\mathrm{x}}^{\mathrm{t}}, \hat{\mathrm{y}}^{\mathrm{t}}\right)}{\left\|\mathrm{E}\left(\hat{\mathrm{x}}^{\mathrm{t}}, \hat{\mathrm{y}}^{\mathrm{t}}\right)\right\|}$ (ignoring those components corresponding to input and output dimensions that cannot be improved if moving in that direction) from the current IBT $\left(\hat{\mathrm{x}}^{\mathrm{t}}, \hat{\mathrm{y}}^{\mathrm{t}}\right)$. In principle, the model tries to move the given stepsize $\Delta$. However, if that is not feasible then the next IBT $\left(\hat{\mathrm{x}}^{\mathrm{t}+1}, \hat{\mathrm{y}}^{\mathrm{t}+1}\right)$ corresponds to moving as much as possible along the EFV direction until any of the dimensions in the sets $\mathrm{I}_{\mathrm{t}}^{-}$and $\mathrm{O}_{\mathrm{t}}^{+}$cannot improve more. Note that this is a simple Goal Programming model where the goal is the desired stepsize $\Delta$ and $\delta^{-}$and $\delta^{+}$are the negative and positive deviations respectively. The achievement function (20) penalizes both types of deviation. Note also that the above model is always feasible and bounded. This can be seen taking into account that the current IBT $\left(\hat{\mathrm{x}}^{\mathrm{t}}, \hat{\mathrm{y}}^{\mathrm{t}}\right)$ is a feasible solution with an associated objective function value of $\Delta$ (corresponding to a value of $\delta=\delta^{+}=0$ and $\delta^{-}=\Delta$ ). Therefore, if giving the whole $\Delta$ step size keeps us within the PPS then it is feasible. Otherwise some input and/or output dimensions reach their PPS limit and no further improvement in those dimensions can be pursued. In other words, some input and/or output dimensions may limit the advancement along the negative gradient direction and prevent the step size from reaching its desired value $\Delta$, thus determining the maximum feasible step size.

If the next IBT $\left(\hat{\mathrm{x}}^{\mathrm{t}+1}, \hat{\mathrm{y}}^{\mathrm{t}+1}\right)$ has been computed, a new iteration (step $\left.\mathrm{t}+1\right)$ is carried out. If the new IBT is technically efficient, the ID DEA model will not find any feasible improvement dimensions and that IBT is the UBT. Conversely, if the new IBT is not technically efficient, then it is still possible to continue improving efficiency along certain input and output dimensions that the corresponding ID DEA model will determine. 
Note that there does not exist an optimal value for the $\Delta$ parameter. That parameter controls the stepsize, i.e. the amount of input and output changes in each step of the stepwise efficiency improvement program. That depends on the DMU, and specifically on how fast it wishes to achieve efficiency. A high value of the $\Delta$ parameter allows larger input and output changes in each step, which means that the efficient frontier can be reached in few steps. On the contrary, a small value of the $\Delta$ parameter means that smaller input and output changes are allowed in each step and therefore more steps will be required to achieve efficiency.

It should be emphasized that the computed stepwise benchmarking path and, hence the UBT, depends on the value of $\Delta$ chosen. However, we see this parameter dependence more as a plus than as a con. Thus, the proposed approach has the flexibility/degree of freedom to allow the analyst, together with the DMU, try several values of the $\Delta$ parameter and select the efficiency improvement path that best suits its interests and its capacities. In other words, when designing a stepwise benchmarking approach, having the possibility of choosing among different UBT may be advantageous, provided they are all efficient. In any case, it is more important to correctly determine the amount of change, i.e. the effort and likelihood of success, involved in each step of the efficiency improvement path than the exact final UBT to aim for.

A possibility, kindly indicated by one reviewer, consists in using a different value of $\Delta$ for each DMU. Also, the value of $\Delta$ could be modified (e.g. reduced) from one step to the next, which can be justified as at first large efficiency improvements may be easier to carry out while at latter stages additional improvements may be harder to achieve.

Finally, note that the proposed efficiency improvement path follows the direction of the gradient (actually the negative gradient) and hence always points to reducing inputs and increasing outputs. This means that the UBT of a given DMU 0 will always dominate it. The minimum EFP (MEFP) model formulated below computes the feasible operating point with minimum EFP. That operating point does not generally dominate a given DMU 0. In other words, although the UBT of the efficiency improvement path has lower EFP than the starting DMU 0, it is not normally a MEFP operating point. Moving to such MEFP operating point once the UBT has been reached can be conceived (as a continuation of the proposed efficiency improvement path) but then, unlike what occurs along the efficiency improvement path, in this case the changes required will necessarily involve either input increases or output reductions. This is because we are talking about moving from one Pareto efficient point to another. In any case, the final efficient, minimum EFP target can be computed by solving the following non-linear optimization model 


\section{MEFP DEA model}

$\operatorname{Min} \sum_{\mathrm{i}=1}^{\mathrm{m}} \log \left(\hat{\mathrm{x}}_{\mathrm{i}}\right)-\sum_{\mathrm{k}=1}^{\mathrm{s}} \log \left(\hat{\mathrm{y}}_{\mathrm{k}}\right)$

s.t.

$\sum_{j=1}^{n} \lambda_{j} \hat{x}_{i j} \leq \hat{x}_{i} \quad \forall i \in I$

$\sum_{j=1}^{n} \lambda_{j} \hat{y}_{k j} \geq \hat{y}_{k} \quad \forall k \in O$

$\sum_{j=1}^{n} \lambda_{j}=1$

$\lambda_{j} \geq 0 \quad j=1,2, \ldots, n$

An LP version of the above model cannot be formulated as long as the non-linear definition of the EFP given in (4) is considered. Although this is a drawback, note that this MEFP DEA model plays a minor role in the proposed path approach. Moreover, it is possible to use an additive-type definition for the EFP which would render the corresponding MEFP DEA model a linear program. In any case, the MEFP model is not actually used in the computation of the stepwise efficiency improvement path. It has been formulated so that the corresponding minimum efficiency potential can be used as a reference value for the efficiency potentials of the observed DMUs and of the computed IBT. What is important is that, of the two main models used in the iterative process for computing the stepwise benchmarking path, the ID DEA model (14)-(18) is MILP and the GSS DEA model (20)-(27) is LP, both of which can be easily solved using any common optimization package (e.g. LINGO or CPLEX).

\subsection{Illustrative example}

In this section the seven DMUs, two outputs/constant input dataset in Cooper et al. (2007, Chapter 1) shown in Table 2, is considered. DMUs B, E, F and G are efficient. Table 2 also shows the corresponding dimensionless input and output vectors (computed using $\mathrm{x}^{\text {aver }}=1, \mathrm{y}_{1}^{\text {aver }}=3.5714$ and $\left.\mathrm{y}_{2}^{\text {aver }}=4.5714\right)$ as well as the associated efficiency potentials. 
Table 3 shows the ten-step efficiency improvement path for DMU A computed using the iterative approach described in section 3.1 using stepsizes $\varepsilon=0.0001$ and $\Delta=0.1$. For each step the current operating point $\left(\hat{\mathrm{x}}^{\mathrm{t}}, \hat{\mathrm{y}}^{\mathrm{t}}\right)$, the improvement dimensions $\mathrm{I}_{\mathrm{t}}^{-}$and $\mathrm{O}_{\mathrm{t}}^{+}$, the EFP $P\left(\hat{x}^{t}, \hat{y}^{t}\right)$ and its gradient, are shown. Also, for reference, the radial output efficiency score of each operating point is shown. Table 4 shows the alternative shorter (five-step) efficiency improvement path computed for the same DMU but using a stepsize $\Delta=0.2$. Note that every step moving along the EFV direction leads to increasing both outputs while the input stays constant. Hence, the efficiency potential decreases in each step and the radial efficiency $\theta^{\mathrm{BCC}-\mathrm{O}}$ increases. The end of the efficiency improvement paths is found when $\mathrm{I}_{\mathrm{t}}^{-}=\mathrm{O}_{\mathrm{t}}^{+}=\varnothing$ which indicates a technically efficient operating point. As expected, in the case of $\Delta=0.2$, the improvements are larger than in the case $\Delta=0.1$. Also, rather interestingly, the UBT is different in both cases, with the $\Delta=0.2$ UBT having a slightly lower potential (0.7699 versus 0.7794$)$.

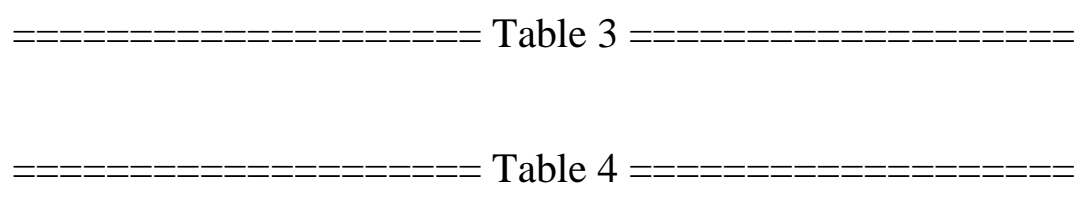

Table 5 shows the efficiency improvement paths for the three inefficient DMUs (using $\Delta=0.2$ ) expressed in the original units of measurement. Figure 2 shows these stepwise efficiency improvement paths. In all cases, the two outputs and the radial $\theta^{\mathrm{BCC}-\mathrm{O}}$ efficiency increase monotonously and the final UBT lies on the technical efficiency frontier. Note that for DMUs C and D it only takes six steps to reach the EF. None of these UBTs, however, corresponds to the MEFP operating point. For this dataset, the MEFP operating point corresponds to DMU F, which is the feasible operating point at which the efficiency equipotential surface of minimum potential is tangent to the PPS. 


\section{Extensions of the proposed approach}

In this section some possible extensions of the proposed approach are presented. Although, in order to simplify exposition they are treated independently, the corresponding features can be present simultaneously.

\subsection{Preference structure}

If there is a preference structure or value judgment on the importance of the different inputs and outputs, this can be taken into account in the proposed approach. Thus, let $\alpha_{i}^{\mathrm{X}}$ and $\alpha_{\mathrm{k}}^{\mathrm{y}}$ be the weights that reflect such relative importance and let us assume that $\sum_{i \in \mathrm{I}} \alpha_{\mathrm{i}}^{\mathrm{x}}+\sum_{\mathrm{k} \in \mathrm{O}} \alpha_{\mathrm{k}}^{\mathrm{y}}=1$. In this case the EFP can be defined as

$$
P(\hat{x}, \hat{y})=\frac{\prod_{i=1}^{m}\left(\hat{x}_{i}\right)^{\alpha_{i}^{x}}}{\prod_{k=1}^{s}\left(\hat{y}_{k}\right)^{\alpha_{k}^{y}}}
$$

whose gradient is

$$
\begin{gathered}
\frac{\partial \mathrm{P}}{\partial \hat{\mathrm{x}}_{\mathrm{i}}}=\frac{\alpha_{\mathrm{i}}^{\mathrm{x}} \cdot\left(\hat{\mathrm{x}}_{\mathrm{i}}\right)^{\alpha_{\mathrm{i}}^{\mathrm{x}}-1} \cdot \prod_{\mathrm{i}^{\prime} \neq \mathrm{i}}\left(\hat{\mathrm{x}}_{\mathrm{i}^{\prime}}\right)^{\alpha_{\mathrm{i}^{\prime}}^{\mathrm{x}}}}{\prod_{\mathrm{k} \in \mathrm{O}}\left(\hat{\mathrm{y}}_{\mathrm{k}}\right)^{\alpha_{\mathrm{k}}^{\mathrm{y}}}}=\frac{\alpha_{\mathrm{i}}^{\mathrm{x}} \cdot \mathrm{P}(\hat{\mathrm{x}}, \hat{\mathrm{y}})}{\hat{\mathrm{x}}_{\mathrm{i}}} \quad \forall \mathrm{i} \\
\frac{\partial \mathrm{P}}{\partial \hat{\mathrm{y}}_{\mathrm{k}}}=-\frac{\alpha_{\mathrm{k}}^{\mathrm{y}} \cdot\left(\hat{\mathrm{y}}_{\mathrm{k}}\right)^{-\alpha_{\mathrm{k}}^{\mathrm{y}}-1} \prod_{\mathrm{i} \in \mathrm{I}}\left(\hat{\mathrm{x}}_{\mathrm{i}}\right)^{\alpha_{\mathrm{i}}^{\mathrm{x}}}}{\prod_{\mathrm{k}^{\prime} \neq \mathrm{k}}\left(\hat{\mathrm{y}}_{\mathrm{k}^{\prime}}\right)^{\alpha_{\mathrm{k}^{\prime}}^{\mathrm{y}}}}=-\frac{\alpha_{\mathrm{k}}^{\mathrm{y}} \cdot \mathrm{P}(\hat{\mathrm{x}}, \hat{\mathrm{y}})}{\hat{\mathrm{y}}_{\mathrm{k}}} \quad \forall \mathrm{k}
\end{gathered}
$$

Compared with (7) it can be seen that the basic change is that the components of the EFP gradient have to be multiplied by the preference weights $\alpha_{i}^{\mathrm{x}}$ and $\alpha_{\mathrm{k}}^{\mathrm{y}}$. This has to be taken into account in constraints (21) and (23) of the GSS DEA model. The ID DEA model is unaffected, while the objective function of MEFP DEA model also changes to 
$\operatorname{Min} \sum_{\mathrm{i}=1}^{\mathrm{m}} \alpha_{\mathrm{i}}^{\mathrm{x}} \cdot \log \left(\hat{\mathrm{x}}_{\mathrm{i}}\right)-\sum_{\mathrm{k}=1}^{\mathrm{s}} \alpha_{\mathrm{k}}^{\mathrm{y}} \cdot \log \left(\hat{\mathrm{y}}_{\mathrm{k}}\right)$

\subsection{Non-discretionary variables}

Let $\mathrm{I}^{\mathrm{ND}}$ and $\mathrm{O}^{\mathrm{ND}}$ be the sets of non-discretionary inputs and outputs, respectively. Let $\mathrm{I}^{\mathrm{D}}=\mathrm{I} \backslash \mathrm{I}^{\mathrm{ND}}$ and $\mathrm{O}^{\mathrm{D}}=\mathrm{O} \backslash \mathrm{O}^{\mathrm{ND}}$ and $\mathrm{m}^{\prime}=\left|\mathrm{I}^{\mathrm{D}}\right|$ and $\mathrm{s}^{\prime}=\left|\mathrm{O}^{\mathrm{D}}\right|$ be the number of discretionary inputs and discretionary outputs, respectively.

The ID DEA model changes slightly as the non-discretionary dimensions are not considered as candidates for improvement. Hence

Modified ID DEA model (iteration $\mathrm{t}$ )

$\operatorname{Max} \sum_{i \in I^{D}} u_{i}+\sum_{k \in O^{D}} v_{k}$

s.t.

$\sum_{j=1}^{n} \lambda_{j} \hat{x}_{i j} \leq \hat{x}_{i}^{t}+\varepsilon \cdot \frac{E_{i}\left(\hat{x}^{t}, \hat{y}^{t}\right)}{\left\|E\left(\hat{x}^{t}, \hat{y}^{t}\right)\right\|} \cdot u_{i} \quad \forall i \in I^{D}$

$\sum_{j=1}^{\mathrm{n}} \lambda_{\mathrm{j}} \hat{\mathrm{x}}_{\mathrm{ij}} \leq \hat{\mathrm{x}}_{\mathrm{i}}^{\mathrm{t}} \quad \forall \mathrm{i} \in \mathrm{I}^{\mathrm{ND}}$

$\sum_{j=1}^{n} \lambda_{j} \hat{y}_{k j} \geq \hat{y}_{k}^{t}+\varepsilon \cdot \frac{E_{k}\left(\hat{x}^{t}, \hat{y}^{t}\right)}{\left\|E\left(\hat{x}^{t}, \hat{y}^{t}\right)\right\|} \cdot v_{k} \quad \forall k \in O^{D}$

$\sum_{j=1}^{\mathrm{n}} \lambda_{\mathrm{j}} \hat{\mathrm{y}}_{\mathrm{kj}} \geq \hat{\mathrm{y}}_{\mathrm{k}}^{\mathrm{t}} \quad \forall \mathrm{k} \in \mathrm{O}^{\mathrm{ND}}$

$\sum_{j=1}^{n} \lambda_{j}=1$

$\lambda_{\mathrm{j}} \geq 0 \quad \mathrm{j}=1,2, \ldots, \mathrm{n} \quad \mathrm{u}_{\mathrm{i}} \in\{0,1\} \forall \mathrm{i} \in \mathrm{I}^{\mathrm{D}} \quad \mathrm{v}_{\mathrm{k}} \in\{0,1\} \forall \mathrm{k} \in \mathrm{O}^{\mathrm{D}}$ 
The improvement dimensions sets are now defined as

$$
\mathrm{I}_{\mathrm{t}}^{-}=\left\{\mathrm{i} \in \mathrm{I}^{\mathrm{D}}: \mathrm{u}_{\mathrm{i}}=1\right\} \quad \mathrm{O}_{\mathrm{t}}^{+}=\left\{\mathrm{k} \in \mathrm{O}^{\mathrm{D}}: \mathrm{v}_{\mathrm{k}}=1\right\}
$$

With respect to the GSS DEA model, there is no change in the formulation. The MEFP DEA model also requires some minor changes as shown below. In particular, since the MEFP operating target of a DMU is constrained by the corresponding values of the nondiscretionary inputs and outputs, that MEFP depends on the DMU being projected.

\section{$\underline{\text { Modified MEFP DEA model }}$}

$\operatorname{Min} \sum_{i \in I^{D}} \log \left(\hat{x}_{i}\right)-\sum_{k \in O^{D}} \log \left(\hat{y}_{k}\right)$

s.t.

$\sum_{j=1}^{n} \lambda_{j} \hat{x}_{i j} \leq \hat{x}_{i} \quad \forall i \in I^{D}$

$\sum_{j=1}^{\mathrm{n}} \lambda_{\mathrm{j}} \hat{\mathrm{x}}_{\mathrm{ij}} \leq \hat{\mathrm{x}}_{\mathrm{i} 0} \quad \forall \mathrm{i} \in \mathrm{I}^{\mathrm{ND}}$

$\sum_{j=1}^{n} \lambda_{j} \hat{y}_{k j} \geq \hat{y}_{k} \quad \forall k \in O^{D}$

$\sum_{\mathrm{j}=1}^{\mathrm{n}} \lambda_{\mathrm{j}} \hat{\mathrm{y}}_{\mathrm{kj}} \geq \hat{\mathrm{y}}_{\mathrm{k} 0} \quad \forall \mathrm{k} \in \mathrm{O}^{\mathrm{ND}}$

$\sum_{j=1}^{n} \lambda_{j}=1$

$\lambda_{j} \geq 0 \quad j=1,2, \ldots, n$

\subsection{Undesirable outputs}

Let $\mathrm{B}$ be the set of undesirable outputs and $\mathrm{p}=|\mathrm{B}|$ the number of undesirable outputs.

Let $\mathrm{z}_{\mathrm{bj}}$ be the amount of undesirable output $\mathrm{b}$ produced by DMU $\mathrm{j}$ and $\hat{z}_{\mathrm{bj}}=\frac{\mathrm{z}_{\mathrm{bj}}}{\mathrm{z}_{\mathrm{b}}^{\mathrm{aver}}}$ the corresponding dimensionless value. The EFP can then be defined as 


$$
P(\hat{x}, \hat{y}, \hat{z})=\frac{\prod_{i=1}^{m} \hat{x}_{i} \cdot \prod_{b=1}^{p} \hat{z}_{b}}{\prod_{k=1}^{s} \hat{y}_{k}}
$$

which means that the components of the EFV are

$$
\begin{aligned}
& E(\hat{x}, \hat{y}, \hat{z})=-\nabla P(\hat{x}, \hat{y}, \hat{z})= \\
& =\left(-\frac{P(\hat{x}, \hat{y}, \hat{z})}{\hat{x}_{1}}, \ldots,-\frac{P(\hat{x}, \hat{y}, \hat{z})}{\hat{x}_{m}}, \frac{P(\hat{x}, \hat{y}, \hat{z})}{\hat{y}_{1}}, \ldots, \frac{P(\hat{x}, \hat{y}, \hat{z})}{\hat{y}_{s}},-\frac{P(\hat{x}, \hat{y}, \hat{z})}{\hat{z}_{1}}, \ldots,-\frac{P(\hat{x}, \hat{y}, \hat{z})}{\hat{z}_{p}}\right)
\end{aligned}
$$

Assuming weak disposability of the undesirable outputs and using the approach in Kuosmanen (2005), the corresponding modified models are

\section{Modified ID DEA model (iteration $\mathrm{t}$ )}

$\operatorname{Max} \sum_{\mathrm{i}=1}^{\mathrm{m}} \mathrm{u}_{\mathrm{i}}+\sum_{\mathrm{k}=1}^{\mathrm{s}} \mathrm{v}_{\mathrm{k}}+\sum_{\mathrm{b}=1}^{\mathrm{p}} \mathrm{w}_{\mathrm{b}}$

s.t.

$\sum_{j=1}^{n}\left(\lambda_{j}+\mu_{j}\right) \cdot \hat{x}_{i j} \leq \hat{x}_{i}^{t}+\varepsilon \cdot \frac{E_{i}\left(\hat{x}^{t}, \hat{y}^{t}, \hat{z}^{t}\right)}{\left\|E\left(\hat{x}^{t}, \hat{y}^{t}, \hat{z}^{t}\right)\right\|} \cdot u_{i} \quad \forall i$

$\sum_{j=1}^{\mathrm{n}} \lambda_{\mathrm{j}} \hat{\mathrm{y}}_{\mathrm{kj}} \geq \hat{\mathrm{y}}_{\mathrm{k}}^{\mathrm{t}}+\varepsilon \cdot \frac{\mathrm{E}_{\mathrm{k}}\left(\hat{\mathrm{x}}^{\mathrm{t}}, \hat{\mathrm{y}}^{\mathrm{t}}, \hat{\mathrm{z}}^{\mathrm{t}}\right)}{\left\|\mathrm{E}\left(\hat{\mathrm{x}}^{\mathrm{t}}, \hat{\mathrm{y}}^{\mathrm{t}}, \hat{\mathrm{z}}^{\mathrm{t}}\right)\right\|} \cdot \mathrm{v}_{\mathrm{k}} \quad \forall \mathrm{k}$

$\sum_{j=1}^{n} \lambda_{j r} \hat{z}_{b j}=\hat{z}_{b}^{t}+\varepsilon \cdot \frac{E_{k}\left(\hat{x}^{t}, \hat{y}^{t}, \hat{z}^{t}\right)}{\left\|E\left(\hat{x}^{t}, \hat{y}^{t}, \hat{z}^{t}\right)\right\|} \cdot w_{b} \quad \forall b$

$\sum_{j=1}^{n}\left(\lambda_{j}+\mu_{j}\right)=1$

$\lambda_{\mathrm{j}} \geq 0 \mu_{\mathrm{j}} \geq 0 \quad \forall \mathrm{j} \quad \mathrm{u}_{\mathrm{i}} \in\{0,1\} \forall \mathrm{i} \quad \mathrm{v}_{\mathrm{k}} \in\{0,1\} \forall \mathrm{k} \quad \mathrm{w}_{\mathrm{b}} \in\{0,1\} \forall \mathrm{b}$

$\mathrm{I}_{\mathrm{t}}^{-}=\left\{\mathrm{i}: \mathrm{u}_{\mathrm{i}}=1\right\} \quad \mathrm{O}_{\mathrm{t}}^{+}=\left\{\mathrm{k}: \mathrm{v}_{\mathrm{k}}=1\right\} \quad \mathrm{B}_{\mathrm{t}}^{-}=\left\{\mathrm{b}: \mathrm{w}_{\mathrm{b}}=1\right\}$ 


\section{$\underline{\text { Modified GSS DEA model (iteration } \mathrm{t} \text { ) }}$}

$\operatorname{Min} \delta^{-}+\delta^{+}$

s.t.

$\sum_{j=1}^{n}\left(\lambda_{j}+\mu_{j}\right) \cdot \hat{x}_{i j} \leq \hat{x}_{i}^{t+1}=\hat{x}_{i}^{t}+\delta \cdot \frac{E_{i}\left(\hat{x}^{t}, \hat{y}^{t}, \hat{z}^{t}\right)}{\left\|E\left(\hat{x}^{t}, \hat{y}^{t}, \hat{z}^{t}\right)\right\|} \quad \forall i \in I_{t}^{-}$

$\sum_{j=1}^{n}\left(\lambda_{j}+\mu_{j}\right) \cdot \hat{x}_{i j} \leq \hat{x}_{i}^{t+1}=\hat{x}_{i}^{t} \quad \forall i \notin I_{t}^{-}$

$\sum_{j=1}^{\mathrm{n}} \lambda_{j} \hat{y}_{\mathrm{kj}} \geq \hat{y}_{\mathrm{k}}^{\mathrm{t}+1}=\hat{\mathrm{y}}_{\mathrm{k}}^{\mathrm{t}}+\delta \cdot \frac{\mathrm{E}_{\mathrm{k}}\left(\hat{\mathrm{x}}^{\mathrm{t}}, \hat{\mathrm{y}}^{\mathrm{t}}, \hat{\mathrm{z}}^{\mathrm{t}}\right)}{\left\|\mathrm{E}\left(\hat{\mathrm{x}}^{\mathrm{t}}, \hat{\mathrm{y}}^{\mathrm{t}}, \hat{\mathrm{z}}^{\mathrm{t}}\right)\right\|} \quad \forall \mathrm{k} \in \mathrm{O}_{\mathrm{t}}^{+}$

$\sum_{j=1}^{n} \lambda_{j} \hat{y}_{k j} \geq \hat{y}_{k}^{t+1}=\hat{y}_{k}^{t} \quad \forall k \notin O_{t}^{+}$

$\sum_{j=1}^{n} \lambda_{j} \hat{z}_{b j}=\hat{z}_{b}^{t+1}=\hat{z}_{b}^{t}+\delta \cdot \frac{E_{b}\left(\hat{x}^{t}, \hat{y}^{t}, \hat{z}^{t}\right)}{\left\|E\left(\hat{x}^{t}, \hat{y}^{t}, \hat{z}^{t}\right)\right\|} \quad \forall b \in B_{t}^{-}$

$\sum_{j=1}^{n} \lambda_{j} \hat{z}_{b j}=\hat{z}_{b}^{t+1}=\hat{z}_{b}^{t} \quad \forall b \notin B_{t}^{-}$

$\sum_{j=1}^{n}\left(\lambda_{j}+\mu_{j}\right)=1$

$\delta+\delta^{-}-\delta^{+}=\Delta$

$\lambda_{\mathrm{j}} \geq 0 \quad \mu_{\mathrm{j}} \geq 0 \quad \mathrm{j}=1,2, \ldots, \mathrm{n} \quad \delta \geq 0 \quad \delta^{-} \geq 0 \quad \delta^{+} \geq 0$

\section{$\underline{\text { Modified MEFP DEA model }}$}

$\operatorname{Min} \sum_{\mathrm{i}=1}^{\mathrm{m}} \log \left(\hat{\mathrm{x}}_{\mathrm{i}}\right)-\sum_{\mathrm{k}=1}^{\mathrm{s}} \log \left(\hat{\mathrm{y}}_{\mathrm{k}}\right)+\sum_{\mathrm{b}=1}^{\mathrm{p}} \log \left(\hat{\mathrm{z}}_{\mathrm{b}}\right)$

s.t. 


$$
\begin{aligned}
& \sum_{j=1}^{n}\left(\lambda_{j}+\mu_{j}\right) \cdot \hat{x}_{i j} \leq \hat{x}_{i} \quad \forall i \in I \\
& \sum_{j=1}^{n} \lambda_{j} \hat{y}_{k j} \geq \hat{y}_{k} \quad \forall k \in O \\
& \sum_{j=1}^{n} \lambda_{j} \hat{z}_{b j}=\hat{z}_{b} \quad \forall b \in B \\
& \sum_{j=1}^{n}\left(\lambda_{j}+\mu_{j}\right)=1 \\
& \lambda_{j} \geq 0 \mu_{j} \geq 0 \quad j=1,2, \ldots, n
\end{aligned}
$$

\section{Application to organic farming benchmarking}

The proposed approach has been applied to a dataset consisting of 26 organic farms in Southern Spain. The unit of analysis is 1 ha. of land of each of the 26 farms. Using a slacksbased inefficiency measure (SBI), an efficiency assessment of the DMUs has been carried out in Gutiérrez et al. (2017), which found that 12 DMUs were technically efficient. In this section we will compute, for each inefficient DMU, a stepwise benchmarking path using the proposed gradient-based approach. Note that the dataset has three inputs, namely Fuel consumption (in litres/ha), Total Carbon input (in $\mathrm{kg} \mathrm{C} / \mathrm{ha}$ ) and Total Nitrogen input (in $\mathrm{kg}$ $\mathrm{N} / \mathrm{ha}$ ), of which the Total $\mathrm{C}$ input is considered non-discretionary. There are also three outputs, namely Yield fresh matter (in $\mathrm{Mg} / \mathrm{ha}$ ), Net Primary Production (excl. fresh matter yield) (NPP) (in Mg dry matter/ha) and $\mathrm{CO}_{2}$ emissions (in $\mathrm{kg} \mathrm{CO}_{2} \mathrm{eq} / \mathrm{ha}$ ), the latter being an undesirable output.

Table 6 shows the inputs and outputs of the 12 efficient DMUs. In addition to these observed DMUs, the virtual average DMU is shown. For each operating point, its EFP is shown in the last column. Note that, since the efficient DMUs occupy different positions in the input/output space, their associated EFP values also differ, although they are low in general (often much lower than the EFP value of the average DMU, which, by definition, is equal to unity). This is so because, on the one hand, EFP is lower the lower the input consumption, the lower the undesirable output production and the higher the desirable output production and, on the other hand, efficient DMUs tend to consume fewer input, produce more desirable output and less undesirable output. Hence, their EFP is expected to be low. 
Their EFP might be possibly reduced a bit but not through technical efficiency improvement, as they are already technical efficient. In other words, their outputs can be increased but only if their inputs consumption and $\mathrm{CO}_{2}$ emissions also increase. Similarly, their input consumption and or their $\mathrm{CO}_{2}$ emissions can be decreased, but only if their outputs also decrease.

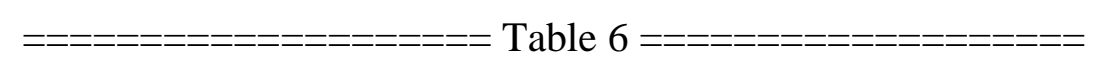

Table 7 shows, the inputs and outputs for each of the 14 inefficient DMUs, as well as those of the UBT of the proposed stepwise efficiency improvement path computed using $\varepsilon=0.0001$ and $\Delta=0.2$. The number of steps required, the EFP of both operating points and their efficiency score computed using the SBI DEA model of Gutiérrez et al. (2017) are also shown. Note that the number of steps of the efficiency improvement paths varies from 3 to 9 , and depends on how far the initial DMU is from the EF. Although, as indicated above, the same value of $\Delta$ has been used for all DMUs, that is not compulsory. The value of $\Delta$ used can vary from one DMU to another so that the computation of the stepwise benchmarking path can be adapted to the circumstances and wishes of each DMU. In particular, the amount of input and output changes a DMU may be willing to implement may depend on their inefficiency level and on the speed with which it wishes to reach technical efficiency.

Note that in all cases the UBT of the efficiency improvement paths as well as the MEFP target are technical efficient. The UBT has a lower potential than the initial DMU, although higher than the MEFP target. Note also that the change in the inputs, outputs and undesirable output along the efficiency improvement path is monotonous, while moving from the UBT to the MEFP generally involves increasing some inputs (and possible also some outputs) or decreasing some outputs (generally decreasing the inputs and the undesirable output as well). The changes from the UBT to the MEFP may also involve input substitution effects (i.e. increasing some inputs while reducing others) or some output substitution (i.e. increasing some outputs at the expense of others). In the absence of information about input and output prices, the advantages of such changes cannot be assessed. That is unlike the changes computed by the efficiency improvement path, which never lead to increasing the inputs or the undesirable output nor to decreasing the desirable outputs and thus are always guaranteed not only to increase efficiency but also to increase profit. 
Figure 3 shows the SBI score of the DMUs versus their corresponding EFP. The efficient DMUs have SBI equal to zero and therefore lie on the horizontal axis. As mentioned before, these efficient DMUs have different EFP values but, in general, they are lower than those of the inefficient DMUs. For the latter, there is a positive correlation between their SBI and EFP values.

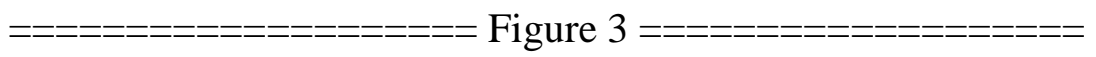

Panel a) of Figure 4 shows the amount of EFP and SBI reduction from the observed DMU to the UBT of its efficiency improvement path. Recall that those UBT are efficient (i.e. have SBI equal zero) which means that the SBI reduction of each DMU is equal to its corresponding SBI score. Note that the DMUs that have large SBI reductions (like O14, O7, $\mathrm{O} 23, \mathrm{O} 3$ or $\mathrm{O} 4)$ are also the ones that also achieve the largest EFP reduction. This positive correlation between SBI and EFP reductions is more noticeable in panel b).

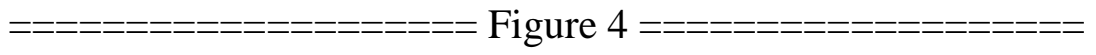

\section{Conclusions}

In this paper, a new stepwise benchmarking approach is presented. It is based on innovative concepts such as efficiency field potential, efficiency equipotential surfaces and efficiency field vector. The idea is to associate an EFP to each feasible operating point so that the smaller the inputs consumption and the larger the outputs production, the smaller the EFP. Moreover, the negative EFP gradient represents the direction of maximum efficiency improvement and always leads to input reductions and outputs increases. Such an EFP gradient is easy to compute and changes from one operating point to another. A stepwise gradual efficiency improvement approach is proposed by moving a bounded stepsize along the negative EFP gradient direction. Care has to be taken not to step out of the PPS. The computed stepwise benchmarking path depends on the amount of input and output changes allowed in each step. This allows the proposed approach to adapt to situations in which a DMU is close to (or far from) the efficient frontier and is willing to achieve small (or large) input and output improvements in each step. A different bound on the amount of inputs and output changes can be used for each DMU or for the different steps of the efficiency improvement programs. All this adds flexibility to the proposed approach, thus increasing its applicability. 
The proposed approach can also incorporate a preference structure reflecting the relative importance of the different inputs and outputs. With the appropriate modifications, it can also handle non-discretionary variables and undesirable outputs. Actually, the proposed approach has been applied to an organic farming dataset with non-discretionary inputs and undesirable outputs. The usefulness of the proposed approach for computing bounded stepwise efficiency improvements that end at an efficient operating point has been shown. The length of the stepwise benchmarking paths depends on the distance to the EF from which they start and on the stepsize bound. Different stepsize bounds generally lead to different UBTs.

Although the proposed approach is rather intuitive and effective, it has some limitations. Thus, it cannot handle integer inputs or outputs. Also, the EFP is undefined for those operating points which have zero consumption of a certain input or zero production of a certain output. Dealing with these zero data occurrences is a topic for further research. One possible solution, kindly pointed out by one of the reviewers, is to consider a linear (i.e. additive) definition of the EFP. That would lead to EES that are hyperplanes and EFL that are straight lines (with negative slope for inputs and positive for outputs). In principle it seems possible, and it is a topic for further research, to reformulate the proposed approach for this type of additive EFP. Actually, an additive EFP would be very appropriate in case that the input and output prices were known since then the EFP would be equivalent to the profit function. Such type of profit potential was already considered in Lozano and Calzada-Infante (2017) in the context of dominance networks and using it to compute profit improvement paths would be possible. Alternatively, instead of the local information provided by the efficiency potential gradient, the profit improvement direction proposed in Zofio et al. (2013) can be used to determine a stepwise profit improvement path.

\section{Acknowledgements}

This research was carried out with the financial support of the Spanish Ministry of Science and the European Regional Development Fund (ERDF), grant DPI2013-41469-P. The authors are thankful to the reviewers for their helpful and insightful comments and suggestions.

\section{References}

Amirteimoori, A. and Kordrostami, S., "A Euclidean distance-based measure of efficiency in data envelopment analysis", Optimization, 59, (2010) 985-996 
Ando, K., Kai, A., Maeda, Y. and Sekitani, K., "Least distance based inefficiency measures on the Pareto-efficient frontier in DEA", Journal of the Operations Research Society of Japan, 55 (2012) 73-91

Ando, K., Minamide, M. and Sekitani, K., "Monotonicity of minimum distance inefficiency measures for Data Envelopment Analysis", European Journal of Operational Research, 260, 1 (2017) 232-243

Aparicio, J., "A survey on measuring efficiency through the determination of the least distance in data envelopment analysis", Journal of Centrum Cathedra, 9, 2 (2016) 143-167

Aparicio, J., Cordero, J.M. and Pastor, J.T., "The determination of the least distance to the strongly efficient frontier in Data Envelopment Analysis oriented models: Modelling and computational aspects", Omega, 71 (2017a) 1-10

Aparicio, J., Mahlberg, B., Pastor, J.T. and Sahoo, B.K., "Decomposing technical inefficiency using the principle of least action", European Journal of Operational Research, 239 (2014) 776-785

Aparicio, J. and Pastor, J.T., "A well-defined efficiency measure for dealing with closest targets in DEA", Applied Mathematics and Computation, 219 (2013) 9142-9154

Aparicio, J. and Pastor, J.T., "On how to properly calculate the Euclidean distance-based measure in DEA", Optimization, 63, 3 (2014a) 421-432

Aparicio, J. and Pastor, J.T., "Closest targets and strong monotonicity on the strongly efficient frontier in DEA", Omega, 44 (2014b) 51-57

Aparicio, J., Pastor, J.T., Sainz-Pardo, J.L. and Vidal, F., "Estimating and decomposing overall inefficiency by determining the least distance to the strongly efficient frontier in data envelopment analysis", Operational Research International Journal, (2017b) DOI 10.1007/s12351-017-0339-0

Aparicio, J., Ruíz, J.L. and Sirvent, I., "Closest targets and minimum distance to the Paretoefficient frontier in DEA", Journal of Productivity Analysis, 28 (2007) 209-218

Baek, C. and Lee, J.D., "The relevance of DEA benchmarking information and the LeastDistance Measure", Mathematical and Computer Modelling, 49 (2009) 265-275

Cherchye, L. and Van Puyenbroeck, T., “A comment on multi-stage DEA methodology", Operations Research Letters, 28 (2001) 93-98

Cherchye, L., Moesen, W., Rogge, N. and Van Puyenbroeck, T., "An introduction to 'benefit of the doubt' composite indicators", Social Indicators Research, 82, 1 (2007) 111-145

Cooper W.W., Seiford, L.M. and Zhu, J., Handbook on Data Envelopment Analysis, Springer, 2004

Cooper, W.W., Seiford, L.M. and Tone, K., Data Envelopment Analysis: A Comprehensive Text with Models, Applications, References and DEA-Solver Software, $2^{\text {nd }}$ edition, Springer, New York, 2007

Ebert, U. and Welsch, H., "Meaningful environmental indices: a social choice approach", Journal of Environmental Economics and Management, 47, 2 (2004) 270-283

Estrada, S.A., Song, H.S., Kim, Y.A., Namn, S.H. and Kang, S.C., "A method of stepwise benchmarking for inefficient DMUs based on the proximity-based target selection", Expert Systems with Applications, 36 (2009) 11595-11604

Fang, L., "Centralized resource allocation based on efficiency analysis for step-by-step improvement paths", Omega, 51 (2015) 24-28 
Frei, F.X. and Harker, P.T., "Projections onto efficient frontiers: theoretical and computational extensions to DEA", Journal of Productivity Analysis, 11 (1999) 275-300

Ghahraman, A. and Prior, D., “A learning ladder toward efficiency: Proposing network-based stepwise benchmark selection”, Omega, 63 (2016) 83-93

González, A. and Álvarez, A., "From efficiency measurement to efficiency improvement: The choice of a relevant benchmark", European Journal of Operational Research, 133 (2001) 512-520

Gutiérrez, E., Aguilera, E., Lozano, S. and Guzmán, G.I., “A two-stage DEA approach for quantifying and analysing the inefficiency of conventional and organic rain-fed cereals in Spain", Journal of Cleaner Production, 149 (2017) 335-348

Hong, H.K.,Ha, S.H., Shin C.K., Park, S.C., Kim, S.H., "Evaluating the efficiency of system integration projects using Data Envelopment Analysis (DEA) and machine learning", Expert Systems with Applications, 16, 3 (1999) 283-296

Khodakarami, M., Shabani, A. and Saen, R.F., "A new look at measuring sustainability of industrial parks: A two-stage data envelopment analysis approach", Clean Technologies and Environmental Policy, 16 (2014) 1577-1596

Kuosmanen, T., Weak disposability in nonparametric production analysis with undesirable outputs, American Journal of Agricultural Economics, 87 (2005) 1077-1082

Lim, S., Bae, H. and Lee, L.H., "A study on the selection of benchmarking paths in DEA", Expert Systems with Applications, 38 (2011) 7665-7673

Lozano, S. and Villa, G., "Determining a sequence of targets in DEA", Journal of the Operational Research Society, 56 (2005) 1439-1447

Lozano, S. and Villa, G., "Gradual technical and scale efficiency improvement in DEA", Annals of Operations Research, 173 (2010) 123-136

Lozano, S. and Calzada-Infante, L., "Dominance network analysis of economic efficiency", Expert Systems with Applications, 82 (2017) 53-66

Maital, S. and Vaninsky, A., "Data envelopment analysis with a single DMU: A graphic projected-gradient approach", European Journal of Operational Research, 115 (1999) 518528

Park, J., Bae, H. and Lim, S., "Method of Benchmarking Route Choice Based on the Input Similarity Using DEA", Smart Innovation, Systems and Technologies, 10 (2011) 519-528

Park, J., Bae, H. and Lim, S., "Stepwise Benchmarking Path Selection in DEA", Smart Innovation, Systems and Technologies, 16 (2012a) 477-484

Park, J., Bae, H. and Lim, S., "A DEA-Based Method of Stepwise Benchmark Target Selection with Preference, Direction and Similarity Criteria", International Journal of Innovative Computing, Information and Control, 8 (2012b) 5821-5834

Park, J., Lim, S. and Bae, H., "DEA-Based Port Efficiency Improvement and Stepwise Benchmarking Target Selection", Information, 14, 12C (2012c) 6155-6171

Park, J., Lim, S. and Bae, H., "An Optimization Approach to the Construction of a Sequence of Benchmark Targets in DEA-Based Benchmarking", Journal of the Korean Institute of Industrial Engineers, 40, 6 (2014) 628-641

Park, J. and Sung, S.I., "Integrated Approach to Construction of Benchmarking Network in DEA-Based Stepwise Benchmark Target Selection”, Sustainability, 8, 600 (2016) 
Pastor, J.T. and Aparicio, J., "The relevance of DEA benchmarking information and the Least-Distance Measure: Comment", Mathematical and Computer Modelling, 52 (2010) 397399

Seiford, L.M. and Zhu, J., "Context-dependent data envelopment analysis - Measuring attractiveness and progress", Omega, 31 (2003) 397-408

Sharma, M.J. and Yu, S.J., "Performance based stratification and clustering for benchmarking of container terminals", Expert Systems with Applications, 36 (2009) 5016-5022

Sharma, M.J. and Yu, S.J., "Benchmark optimization and attribute identification for improvement of container terminals", European Journal of Operational Research, 201 (2010) $568-580$

Silva Portela, M.C.A., Castro Borges, P. and Thanassoulis, E., "Finding Closest Targets in Non-Oriented DEA Models: The Case of Convex and Non-Convex Technologies", Journal of Productivity Analysis, 19 (2003) 251-269

Silva Portela, M.C.A. and Thanassoulis, E., "Developing a decomposable measure of profit efficiency using DEA", Journal of the Operational Research Society, 58, 4 (2007) 481-490

Suzuki, S. and Nijkamp, P., "A stepwise-projection data envelopment analysis for public transport operations in Japan”, Letters in Spatial and Resources Sciences, 4 (2011) 139-156

Zhu, J., Quantitative Models for Performance Evaluation and Benchmarking: Data Envelopment Analysis With Spreadsheets and DEA Excel Solver, Kluwer Academic Publishers, Boston, 2002

Zofio, J.L., Pastor, J.T. and Aparicio, J., "The directional profit efficiency measure: on why profit inefficiency is either technical or allocative", Journal of Productivity Analysis, 40 (2013) 257-266 


\section{List of figures and table captions}

Figure 1. Efficiency vector fields for three bidimensional cases

Figure 2. Gradient-based stepwise efficiency improvement paths for DMUs A, C and D $(\Delta=0.2)$

Figure 3. SBI and EFP of efficient and inefficient DMUs

Figure 4. SBI and EFP reductions achieved along the different efficiency improvement paths

Table 1. Summary of existing stepwise efficiency improvement approaches

Table 2. Two output/constant input dataset from Cooper et al. (2007, Chapter 1)

Table 3. Gradient-based stepwise efficiency improvement path for DMU A $(\Delta=0.1)$

Table 4. Gradient-based stepwise efficiency improvement path for DMU A ( $\Delta=0.2)$

Table 5. Efficiency improvement path for DMUs A, C and D $(\Delta=0.2)$ in original units of measurement

Table 6. Efficient DMUs and average DMU of organic farming dataset

Table 7. Summary of stepwise efficiency improvement path of the inefficient DMUs 


\begin{tabular}{|c|c|c|c|c|c|c|c|c|c|}
\hline Reference & IBT & UBT & Stratification & $\begin{array}{l}\text { Benchmark } \\
\text { network }\end{array}$ & $\begin{array}{c}\text { Stepsize } \\
\text { constraints }\end{array}$ & Clustering & Similarity criteria & Zigzagging & Other features \\
\hline $\begin{array}{l}\text { Hong et al. } \\
\text { (1999) }\end{array}$ & $\begin{array}{l}\text { Existing } \\
\text { DMUs }\end{array}$ & $\begin{array}{l}\text { Existing } \\
\text { DMUs }\end{array}$ & Yes (Tiers) & No & No & $\begin{array}{l}\text { SOM (inputs } \\
\text { only) }\end{array}$ & Same cluster & Yes & $\begin{array}{l}\text { Decision tree for } \\
\text { tier classification }\end{array}$ \\
\hline $\begin{array}{l}\text { Lozano and } \\
\text { Villa (2005) }\end{array}$ & $\begin{array}{c}\text { Feasible } \\
\text { operating } \\
\text { points }\end{array}$ & $\begin{array}{c}\text { Efficient } \\
\text { operating } \\
\text { points }\end{array}$ & No & No & $\begin{array}{c}\text { Yes (on the } \\
\text { change of each } \\
\text { variable) }\end{array}$ & No & $\begin{array}{c}\text { Efficiency } \\
\text { improvement }\end{array}$ & No & CRS \\
\hline $\begin{array}{l}\text { Estrada et al. } \\
\qquad(2009)\end{array}$ & $\begin{array}{l}\text { Existing } \\
\text { DMUs }\end{array}$ & $\begin{array}{l}\text { Existing } \\
\text { DMUs }\end{array}$ & No & No & $\begin{array}{l}\text { Yes (on } \\
\text { efficiency } \\
\text { change) }\end{array}$ & $\begin{array}{l}\text { SOM (inputs } \\
\text { only) }\end{array}$ & SOM distance & Yes & $\begin{array}{l}\text { Reinforcement } \\
\text { Learning }\end{array}$ \\
\hline $\begin{array}{l}\text { Sharma and } \\
\text { Yu (2009) }\end{array}$ & $\begin{array}{l}\text { Existing } \\
\text { DMUs }\end{array}$ & $\begin{array}{l}\text { Existing } \\
\text { DMUs }\end{array}$ & Yes (Tiers) & No & No & $\begin{array}{l}\text { SOM (inputs } \\
\text { only) }\end{array}$ & Same cluster & Yes & \\
\hline $\begin{array}{l}\text { Sharma and } \\
\text { Yu (2010) }\end{array}$ & $\begin{array}{l}\text { Existing } \\
\text { DMUs }\end{array}$ & $\begin{array}{l}\text { Existing } \\
\text { DMUs }\end{array}$ & $\begin{array}{c}\text { Yes (Context } \\
\text { dependent } \\
\text { DEA) }\end{array}$ & No & No & No & $\begin{array}{c}\text { Attractiveness and } \\
\text { progress }\end{array}$ & Yes & $\begin{array}{c}\text { Decision tree for } \\
\text { attribute } \\
\text { prioritization }\end{array}$ \\
\hline $\begin{array}{l}\text { Lozano and } \\
\text { Villa (2010) }\end{array}$ & $\begin{array}{l}\text { Feasible } \\
\text { operating } \\
\text { points }\end{array}$ & $\begin{array}{l}\text { MPSS } \\
\text { efficient } \\
\text { operating } \\
\text { points }\end{array}$ & No & No & $\begin{array}{c}\text { Yes (on the } \\
\text { change of each } \\
\text { variable) }\end{array}$ & No & $\begin{array}{c}\text { Efficiency } \\
\text { improvement }\end{array}$ & No & VRS \\
\hline $\begin{array}{l}\text { Park et al. } \\
\quad(2011)\end{array}$ & $\begin{array}{l}\text { Existing } \\
\text { DMUs }\end{array}$ & $\begin{array}{l}\text { Existing } \\
\text { DMUs }\end{array}$ & $\begin{array}{c}\text { Yes (Context } \\
\text { dependent } \\
\text { DEA) }\end{array}$ & No & No & k-means & Inter-cluster distance & Yes & \\
\hline $\begin{array}{l}\text { Lim et al. } \\
\text { (2011) }\end{array}$ & $\begin{array}{l}\text { Existing } \\
\text { DMUs }\end{array}$ & $\begin{array}{l}\text { Existing } \\
\text { DMUs }\end{array}$ & $\begin{array}{c}\text { Yes (Context } \\
\text { dependent } \\
\text { DEA) }\end{array}$ & No & $\begin{array}{c}\text { Yes (joint } \\
\text { linear } \\
\text { constraints) }\end{array}$ & No & $\begin{array}{l}\text { Attractiveness, } \\
\text { progress and } \\
\text { Infeasibility }\end{array}$ & Yes & \\
\hline $\begin{array}{l}\text { Suzuki and } \\
\text { Nijkamp } \\
(2011)\end{array}$ & $\begin{array}{l}\text { Feasible } \\
\text { operating } \\
\text { points }\end{array}$ & $\begin{array}{l}\text { Efficient } \\
\text { operating } \\
\text { points }\end{array}$ & $\begin{array}{c}\text { Yes (Context } \\
\text { dependent } \\
\text { DEA) }\end{array}$ & No & No & No & $\begin{array}{l}\text { Distance friction } \\
\text { minimization }\end{array}$ & Yes & \\
\hline
\end{tabular}

Table 1. Summary of existing stepwise efficiency improvement approaches 


\begin{tabular}{|c|c|c|c|c|c|c|c|c|c|}
\hline Reference & IBT & UBT & Stratification & $\begin{array}{c}\text { Benchmark } \\
\text { network }\end{array}$ & $\begin{array}{c}\text { Stepsize } \\
\text { constraints }\end{array}$ & Clustering & $\begin{array}{l}\text { IBT selection } \\
\text { criteria }\end{array}$ & Zigzagging & Other features \\
\hline $\begin{array}{l}\text { Park et al. } \\
\text { (2012a) }\end{array}$ & $\begin{array}{l}\text { Existing } \\
\text { DMUs }\end{array}$ & $\begin{array}{l}\text { Existing } \\
\text { DMUs }\end{array}$ & $\begin{array}{l}\text { Yes (Context } \\
\text { dependent } \\
\text { DEA) }\end{array}$ & Yes & No & No & $\begin{array}{c}\text { Resource } \\
\text { improvement, } \\
\text { directional proximity } \\
\text { (inputs) }\end{array}$ & Yes & Shortest Path \\
\hline $\begin{array}{l}\text { Park et al. } \\
\text { (2012b) }\end{array}$ & $\begin{array}{l}\text { Existing } \\
\text { DMUs }\end{array}$ & $\begin{array}{l}\text { Existing } \\
\text { DMUs }\end{array}$ & $\begin{array}{l}\text { Yes (Context } \\
\text { dependent } \\
\text { DEA) }\end{array}$ & No & No & $\begin{array}{l}\text { SOM (inputs } \\
\text { only) }\end{array}$ & $\begin{array}{c}\text { SOM distance, } \\
\text { directional proximity } \\
\text { (inputs) }\end{array}$ & Yes & $\begin{array}{l}\text { Preference } \\
\text { structure }\end{array}$ \\
\hline $\begin{array}{l}\text { Park et al. } \\
(2012 c)\end{array}$ & $\begin{array}{l}\text { Existing } \\
\text { DMUs }\end{array}$ & $\begin{array}{l}\text { Existing } \\
\text { DMU }\end{array}$ & $\begin{array}{l}\text { Yes (Context } \\
\text { dependent } \\
\text { DEA) }\end{array}$ & No & No & No & $\begin{array}{l}\text { Least distance } \\
\text { measure }\end{array}$ & Yes & $\begin{array}{l}\text { Resource priority } \\
\text { analysis }\end{array}$ \\
\hline $\begin{array}{l}\text { Khodakarami } \\
\text { et al. (2014) }\end{array}$ & $\begin{array}{l}\text { Feasible } \\
\text { operating } \\
\text { points }\end{array}$ & $\begin{array}{l}\text { MPSS } \\
\text { efficient } \\
\text { operating } \\
\text { points }\end{array}$ & No & No & $\begin{array}{l}\text { Yes (on the } \\
\text { change of each } \\
\text { variable) }\end{array}$ & No & $\begin{array}{l}\text { Ray average } \\
\text { productivity }\end{array}$ & Yes & $\begin{array}{l}\text { Extension to two } \\
\text { stage systems }\end{array}$ \\
\hline $\begin{array}{l}\text { Park et al. } \\
\text { (2014) }\end{array}$ & $\begin{array}{l}\text { Existing } \\
\text { DMUs }\end{array}$ & $\begin{array}{l}\text { Existing } \\
\text { DMUs }\end{array}$ & $\begin{array}{l}\text { Yes (Context } \\
\text { dependent } \\
\text { DEA) }\end{array}$ & Yes & No & $\begin{array}{l}\text { k-means }(\mathrm{XE} \\
\text { matrix) }\end{array}$ & $\begin{array}{l}\text { Same cluster, Least } \\
\text { distance measure }\end{array}$ & Yes & Shortest Path \\
\hline Fang (2015) & $\begin{array}{l}\text { Feasible } \\
\text { operating } \\
\text { points }\end{array}$ & $\begin{array}{l}\text { Efficient } \\
\text { operating } \\
\text { points }\end{array}$ & No & No & $\begin{array}{l}\text { Yes (on } \\
\text { efficiency } \\
\text { change) }\end{array}$ & No & $\begin{array}{l}\text { Efficiency } \\
\text { improvement }\end{array}$ & No & Centralized DEA \\
\hline $\begin{array}{c}\text { Park and } \\
\text { Sung (2016) }\end{array}$ & $\begin{array}{l}\text { Existing } \\
\text { DMUs }\end{array}$ & $\begin{array}{l}\text { Existing } \\
\text { DMUs }\end{array}$ & $\begin{array}{l}\text { Yes (Context } \\
\text { dependent } \\
\text { DEA) }\end{array}$ & Yes & No & $\begin{array}{l}\text { k-means }(\mathrm{XE} \\
\text { matrix) }\end{array}$ & Same cluster & Yes & \\
\hline $\begin{array}{l}\text { Ghahraman \& } \\
\text { Prior (2016) }\end{array}$ & $\begin{array}{l}\text { Existing } \\
\text { DMUs }\end{array}$ & $\begin{array}{l}\text { Existing } \\
\text { DMUs }\end{array}$ & No & Yes & $\begin{array}{l}\text { Yes (on the } \\
\text { change of each } \\
\text { variable) }\end{array}$ & $\begin{array}{c}\text { Network } \\
\text { components }\end{array}$ & $\begin{array}{c}\text { Euclidean distance } \\
\text { (normalized inputs), } \\
\text { efficiency change }\end{array}$ & Yes & $\begin{array}{l}\text { Shortest Path, } \\
\text { Fixed cost }\end{array}$ \\
\hline
\end{tabular}

Notes: IBT=Intermediate Benchmark Targets, UBT=Ultimate Benchmark Targets, CRS=Constant Returns to Scale, VRS=Variable Returns to Scale, MPSS=Most Productive Scale Size, SOM=Self-Organizing Map, XE=Cross-efficiency

Table 1. Summary of existing stepwise efficiency improvement approaches (cont.) 


\begin{tabular}{|c|c|c|c|c|c|c|c|}
\hline DMU $j$ & A & B & C & D & E & F & G \\
\hline $\mathrm{x}_{j}$ & 1 & 1 & 1 & 1 & 1 & 1 & 1 \\
\hline$y_{1 j}$ & 1 & 2 & 3 & 4 & 4 & 5 & 6 \\
\hline$y_{2 j}$ & 5 & 7 & 4 & 3 & 6 & 5 & 2 \\
\hline$\hat{x}_{j}$ & 1 & 1 & 1 & 1 & 1 & 1 & 1 \\
\hline$\hat{y}_{1 j}$ & 0.2800 & 0.5600 & 0.8400 & 1.1200 & 1.1200 & 1.4000 & 1.6800 \\
\hline$\hat{y}_{2 j}$ & 1.0938 & 1.5313 & 0.8750 & 0.6563 & 1.3125 & 1.0938 & 0.4375 \\
\hline$P\left(\hat{x}_{j}, \hat{y}_{1 j}, \hat{y}_{2 j}\right)$ & 3.2653 & 1.1662 & 1.3605 & 1.3605 & 0.6803 & 0.6531 & 1.3605 \\
\hline
\end{tabular}

Table 2. Two output/constant input dataset from Cooper et al. (2007, Chapter 1) 


\begin{tabular}{|c|c|c|c|c|c|c|c|c|c|c|}
\hline Step t & $\hat{\mathrm{x}}^{\mathrm{t}}$ & $\hat{y}_{1}^{t}$ & $\hat{y}_{2}^{t}$ & $\mathrm{I}_{\mathrm{t}}^{-}$ & $\mathrm{O}_{\mathrm{t}}^{+}$ & $\mathrm{P}\left(\hat{\mathrm{x}}^{\mathrm{t}}, \hat{\mathrm{y}}_{1}^{\mathrm{t}}, \hat{\mathrm{y}}_{2}^{\mathrm{t}}\right)$ & $\frac{\partial \mathrm{P}}{\partial \hat{\mathrm{x}}}$ & $\frac{\partial \mathrm{P}}{\partial \hat{\mathrm{y}}_{1}}$ & $\frac{\partial \mathrm{P}}{\partial \hat{\mathrm{y}}_{2}}$ & $\theta^{\mathrm{BCC}-\mathrm{O}}$ \\
\hline 0 & 1 & 0.2800 & 1.0938 & $\varnothing$ & $\{1,2\}$ & 3.2653 & 3.2653 & -11.6618 & -2.9854 & 0.714 \\
\hline 1 & 1 & 0.3735 & 1.1177 & $\varnothing$ & $\{1,2\}$ & 2.395 & 2.3955 & -6.4137 & -2.1433 & 0.730 \\
\hline 2 & 1 & 0.4629 & 1.1476 & $\varnothing$ & $\{1,2\}$ & 1.8825 & 1.8825 & -4.0668 & -1.6405 & 0.759 \\
\hline 3 & 1 & 0.5481 & 1.1819 & $\varnothing$ & $\{1,2\}$ & 1.5436 & 1.5436 & -2.8162 & -1.3060 & 0.798 \\
\hline 4 & 1 & 0.6293 & 1.2196 & $\varnothing$ & $\{1,2\}$ & 1.3028 & 1.3028 & -2.0701 & -1.0682 & 0.837 \\
\hline 5 & 1 & 0.7069 & 1.2596 & $\varnothing$ & $\{1,2\}$ & 1.1230 & 1.1230 & -1.5887 & -0.8916 & 0.878 \\
\hline 6 & 1 & 0.7811 & 1.3013 & $\varnothing$ & $\{1,2\}$ & 0.9838 & 0.9838 & -1.2594 & -0.7560 & 0.918 \\
\hline 7 & 1 & 0.8524 & 1.3441 & $\varnothing$ & $\{1,2\}$ & 0.8729 & 0.8729 & -1.0240 & -0.6494 & 0.958 \\
\hline 8 & 1 & 0.9209 & 1.3875 & $\varnothing$ & $\{1,2\}$ & 0.7826 & 0.7826 & -0.8498 & -0.5640 & 0.998 \\
\hline 9 & 1 & 0.9235 & 1.3892 & $\varnothing$ & $\varnothing$ & 0.7794 & 0.7794 & -0.8440 & -0.5610 & 1.000 \\
\hline
\end{tabular}

Table 3. Gradient-based stepwise efficiency improvement path for DMU A $(\Delta=0.1)$ 


\begin{tabular}{|c|c|c|c|c|c|c|c|c|c|c|}
\hline Step $\mathrm{t}$ & $\hat{\mathrm{x}}^{\mathrm{t}}$ & $\hat{y}_{1}^{\mathrm{t}}$ & $\hat{y}_{2}^{t}$ & $\mathrm{I}_{\mathrm{t}}^{-}$ & $\mathrm{O}_{\mathrm{t}}^{+}$ & $\mathrm{P}\left(\hat{\mathrm{x}}^{\mathrm{t}}, \hat{\mathrm{y}}_{1}^{\mathrm{t}}, \hat{\mathrm{y}}_{2}^{\mathrm{t}}\right)$ & $\frac{\partial \mathrm{P}}{\partial \hat{\mathrm{x}}}$ & $\frac{\partial \mathrm{P}}{\partial \hat{\mathbf{y}}_{1}}$ & $\frac{\partial \mathrm{P}}{\partial \hat{\mathrm{y}}_{2}}$ & $\theta^{\mathrm{BCC}-\mathrm{O}}$ \\
\hline 0 & 1 & 0.2800 & 1.0938 & $\varnothing$ & $\{1,2\}$ & 3.2653 & 3.2653 & -11.6618 & -2.9854 & 0.714 \\
\hline 1 & 1 & 0.4670 & 1.1416 & $\varnothing$ & $\{1,2\}$ & 1.8757 & 1.8757 & -4.0166 & -1.6430 & 0.757 \\
\hline 2 & 1 & 0.6369 & 1.2111 & $\varnothing$ & $\{1,2\}$ & 1.2964 & 1.2964 & -2.0354 & -1.0704 & 0.834 \\
\hline 3 & 1 & 0.7911 & 1.2922 & $\varnothing$ & $\{1,2\}$ & 0.9782 & 0.9782 & -1.2365 & -0.7570 & 0.915 \\
\hline 4 & 1 & 0.9325 & 1.3788 & $\varnothing$ & $\{1,2\}$ & 0.7778 & 0.7778 & -0.8341 & -0.5641 & 0.996 \\
\hline 5 & 1 & 0.9390 & 1.3832 & $\varnothing$ & $\varnothing$ & 0.7699 & 0.7699 & -0.8199 & -0.5566 & 1.000 \\
\hline
\end{tabular}

Table 4. Gradient-based stepwise efficiency improvement path for DMU A $(\Delta=0.2)$

\begin{tabular}{|c|c|c|c|c|c|c|c|c|c|c|c|c|}
\hline \multirow[b]{2}{*}{ Step $\mathrm{t}$} & \multicolumn{4}{|c|}{ DMU A } & \multicolumn{4}{|c|}{ DMU C } & \multicolumn{4}{|c|}{ DMU D } \\
\hline & $x^{t}$ & $\mathrm{y}_{1}^{\mathrm{t}}$ & $\mathrm{y}_{2}^{\mathrm{t}}$ & $\theta^{\mathrm{BCC}-\mathrm{O}}$ & $x^{t}$ & $\mathrm{y}_{1}^{\mathrm{t}}$ & $y_{2}^{t}$ & $\theta^{\mathrm{BCC}-\mathrm{O}}$ & $x^{t}$ & $\mathrm{y}_{1}^{\mathrm{t}}$ & $\mathrm{y}_{2}^{\mathrm{t}}$ & $\theta^{\mathrm{BCC}-\mathrm{O}}$ \\
\hline 0 & 1 & 1 & 5 & 0.714 & 1 & 3 & 4 & 0.700 & 1 & 4 & 3 & 0.750 \\
\hline 1 & 1 & 1.6678 & 5.2188 & 0.757 & 1 & 3.4407 & 4.5415 & 0.798 & 1 & 4.3142 & 3.6864 & 0.831 \\
\hline 2 & 1 & 2.2747 & 5.5366 & 0.834 & 1 & 3.8624 & 5.0650 & 0.893 & 1 & 4.6436 & 4.3180 & 0.912 \\
\hline 3 & 1 & 2.8254 & 5.9073 & 0.915 & 1 & 4.2667 & 5.5700 & 0.984 & 1 & 4.9772 & 4.9057 & 0.992 \\
\hline 4 & 1 & 3.3304 & 6.3030 & 0.996 & 1 & 4.3391 & 5.6609 & 1.000 & 1 & 5.0121 & 4.9638 & 1.000 \\
\hline 5 & 1 & 3.3537 & 6.3232 & 1.000 & - & - & - & - & - & - & - & - \\
\hline
\end{tabular}

Table 5. Efficiency improvement path for DMUs A, C and D $(\Delta=0.2)$ in original units of measurement 


\begin{tabular}{|c|c|c|c|c|c|c|c|}
\hline DMU & $\begin{array}{c}\text { Fuel } \\
\text { consumption }\end{array}$ & Total $\mathrm{C}$ input & Total $\mathrm{N}$ input & $\begin{array}{l}\text { Yield fresh } \\
\text { matter }\end{array}$ & NPP & $\mathrm{CO}_{2}$ emissions & $\mathrm{P}\left(\hat{\mathrm{x}}^{\mathrm{t}}, \hat{\mathrm{y}}^{\mathrm{t}}, \hat{\mathrm{z}}^{\mathrm{t}}\right)$ \\
\hline O1 & 39.30 & 472.18 & 46.40 & $1,880.0$ & $3,109.96$ & 414.36 & 0.8000 \\
\hline O5 & 49.91 & 118.84 & 25.87 & $1,500.0$ & $2,657.88$ & 497.30 & 0.2509 \\
\hline O6 & 48.86 & 104.24 & 23.34 & $1,200.0$ & $2,300.97$ & 473.18 & 0.2671 \\
\hline $\mathrm{O} 10$ & 55.65 & 384.70 & 40.60 & $3,000.0$ & $4,442.42$ & 494.81 & 0.4231 \\
\hline $\mathrm{O} 11$ & 56.52 & $1,297.82$ & 94.23 & $3,000.0$ & $4,442.42$ & 88.18 & 0.5997 \\
\hline $\mathrm{O} 12$ & 55.49 & 228.24 & 32.23 & $2,500.0$ & $3,847.57$ & 523.94 & 0.2915 \\
\hline O15 & 43.14 & 141.08 & 45.24 & $1,800.0$ & $3,201.68$ & 701.83 & 0.4396 \\
\hline O17 & 43.52 & 209.54 & 29.90 & $2,000.0$ & $3,460.38$ & 480.56 & 0.2483 \\
\hline $\mathrm{O} 20$ & 55.85 & 469.99 & 43.26 & $2,600.0$ & $3,541.75$ & 348.11 & 0.5628 \\
\hline $\mathrm{O} 21$ & 42.67 & 372.38 & 50.23 & $2,800.0$ & $3,747.01$ & 384.58 & 0.3835 \\
\hline $\mathrm{O} 22$ & 48.91 & 123.70 & 25.55 & $1,600.0$ & $2,776.85$ & 557.43 & 0.2543 \\
\hline $\mathrm{O} 25$ & 33.90 & $1,252.08$ & 57.13 & $1,500.0$ & $2,813.62$ & 50.36 & 0.3794 \\
\hline Aver. DMU & 48.00 & 514.21 & 45.10 & $1,853.3$ & $3,047.20$ & 386.96 & 1.0000 \\
\hline
\end{tabular}

Table 6. Efficient DMUs and average DMU of organic farming dataset 


\begin{tabular}{|c|c|c|c|c|c|c|c|c|}
\hline & Fuel consump. & Total C input & Total N input & Yield & NPP & $\mathrm{CO}_{2}$ emissions & $\mathrm{P}\left(\hat{\mathrm{x}}^{\mathrm{t}}, \hat{\mathrm{y}}^{\mathrm{t}}, \hat{\mathrm{z}}^{\mathrm{t}}\right)$ & SBI score \\
\hline DMU O2 & 52.48 & 36.96 & 307.35 & $2,000.00$ & $3,252.72$ & 488.50 & 0.587 & 0.117 \\
\hline UBT (Step 3) & 48.00 & 31.96 & 307.35 & $2,151.12$ & $3,503.88$ & 461.00 & 0.378 & 0.000 \\
\hline MEFP O2 & 50.29 & 35.87 & 307.35 & $2,558.40$ & $4,008.75$ & 488.52 & 0.346 & 0.000 \\
\hline DMU O3 & 49.66 & 38.98 & 324.24 & $1,400.00$ & $2,538.91$ & 457.68 & 1.060 & 0.281 \\
\hline UBT (Step 5) & 43.00 & 31.37 & 324.24 & $1,761.77$ & $3,059.96$ & 406.62 & 0.432 & 0.000 \\
\hline MEFP O3 & 42.92 & 44.22 & 324.24 & $2,563.50$ & $3,662.27$ & 412.95 & 0.355 & 0.000 \\
\hline DMU O4 & 47.75 & 48.31 & 526.26 & $1,200.00$ & $2,104.91$ & 271.49 & 1.711 & 0.289 \\
\hline UBT (Step 4) & 42.42 & 43.67 & 526.26 & $1,706.23$ & $2,556.93$ & 208.61 & 0.611 & 0.000 \\
\hline MEFP O4 & 41.14 & 51.44 & 526.26 & $2,572.60$ & $3,583.74$ & 326.12 & 0.516 & 0.000 \\
\hline DMU O7 & 44.69 & 40.64 & 373.53 & $1,000.00$ & $2,063.03$ & 462.66 & 1.995 & 0.471 \\
\hline UBT (Step 7) & 41.40 & 37.44 & 373.53 & $1,734.45$ & $2,968.36$ & 381.77 & 0.563 & 0.000 \\
\hline MEFP O7 & 42.66 & 50.24 & 373.53 & $2,798.30$ & $3,745.79$ & 384.14 & 0.385 & 0.000 \\
\hline DMU O8 & 45.20 & 46.60 & 485.83 & $2,000.00$ & $3,252.72$ & 444.70 & 0.917 & 0.127 \\
\hline UBT (Step 9) & 41.60 & 43.35 & 485.83 & $2,260.84$ & $3,462.53$ & 364.51 & 0.535 & 0.000 \\
\hline MEFP O8 & 41.54 & 51.12 & 485.83 & $2,632.35$ & $3,626.64$ & 341.48 & 0.484 & 0.000 \\
\hline
\end{tabular}

Table 7. Summary of stepwise efficiency improvement path of the inefficient DMUs 


\begin{tabular}{|c|c|c|c|c|c|c|c|c|}
\hline & Fuel consump. & Total C input & Total N input & Yield & NPP & $\mathrm{CO}_{2}$ emissions & $\mathrm{P}\left(\hat{\mathrm{x}}^{\mathrm{t}}, \hat{\mathrm{y}}^{\mathrm{t}}, \hat{\mathrm{z}}^{\mathrm{t}}\right)$ & SBI score \\
\hline DMU O9 & 46.73 & 45.90 & 472.98 & $1,880.00$ & $3,109.96$ & 456.10 & 1.038 & 0.166 \\
\hline UBT (Step 8) & 41.68 & 41.37 & 472.98 & $2,188.84$ & $3,442.79$ & 375.41 & 0.533 & 0.000 \\
\hline MEFP O9 & 41.67 & 51.02 & 472.98 & $2,651.34$ & $3,640.27$ & 346.36 & 0.473 & 0.000 \\
\hline DMU O13 & 51.07 & 36.26 & 318.49 & $2,000.00$ & $3,460.38$ & 498.89 & 0.557 & 0.098 \\
\hline UBT (Step 3) & 46.44 & 32.34 & 318.49 & $2,210.26$ & $3,648.11$ & 477.89 & 0.372 & 0.000 \\
\hline MEFP O13 & 51.06 & 36.56 & 318.49 & $2,622.00$ & $4,071.21$ & 489.42 & 0.357 & 0.000 \\
\hline DMU O14 & 47.27 & 47.88 & 516.38 & $1,000.00$ & $1,899.65$ & 291.75 & 2.353 & 0.420 \\
\hline UBT (Step 5) & 40.84 & 42.31 & 516.38 & $1,563.25$ & $2,477.07$ & 222.18 & 0.671 & 0.000 \\
\hline MEFP O14 & 41.23 & 51.36 & 516.38 & $2,587.20$ & $3,594.22$ & 329.87 & 0.509 & 0.000 \\
\hline DMU O16 & 45.20 & 46.18 & 500.09 & $2,000.00$ & $3,460.38$ & 454.86 & 0.899 & 0.114 \\
\hline UBT (Step 5) & 42.76 & 41.89 & 500.09 & $2,400.77$ & $3,588.81$ & 409.74 & 0.558 & 0.000 \\
\hline MEFP O16 & 41.40 & 51.23 & 500.09 & $2,611.27$ & $3,611.51$ & 336.06 & 0.496 & 0.000 \\
\hline DMU O18 & 56.36 & 48.44 & $1,119.50$ & $1,500.00$ & $2,412.81$ & 154.74 & 1.713 & 0.121 \\
\hline UBT (Step 7) & 42.85 & 47.29 & $1,119.50$ & $1,562.49$ & $2,542.41$ & 128.33 & 0.961 & 0.000 \\
\hline MEFP O18 & 35.63 & 53.23 & $1,119.50$ & $1,326.74$ & $2,488.64$ & 44.54 & 0.375 & 0.000 \\
\hline
\end{tabular}

Table 7. Summary of stepwise efficiency improvement path of the inefficient DMUs (cont.) 


\begin{tabular}{|c|c|c|c|c|c|c|c|c|}
\hline & Fuel consump. & Total $\mathrm{C}$ input & Total $\mathrm{N}$ input & Yield & NPP & $\mathrm{CO}_{2}$ emissions & $\mathrm{P}\left(\hat{\mathrm{x}}^{\mathrm{t}}, \hat{\mathrm{y}}^{\mathrm{t}}, \hat{\mathrm{z}}^{\mathrm{t}}\right)$ & SBI score \\
\hline DMU O19 & 53.11 & 59.86 & 477.46 & $2,500.00$ & $3,439.12$ & 373.85 & 0.865 & 0.111 \\
\hline UBT (Step 5) & 44.60 & 54.73 & 477.46 & $2,726.39$ & $3,701.43$ & 334.40 & 0.506 & 0.000 \\
\hline MEFP O19 & 41.62 & 51.05 & 477.46 & $2,644.72$ & $3,635.52$ & 344.66 & 0.477 & 0.000 \\
\hline DMU O23 & 49.61 & 39.08 & 247.59 & $1,125.00$ & $2,211.74$ & 448.77 & 1.135 & 0.345 \\
\hline UBT (Step 5) & 43.04 & 31.57 & 247.59 & $1,655.48$ & $2,858.31$ & 389.34 & 0.363 & 0.000 \\
\hline MEFP O23 & 46.15 & 32.22 & 247.59 & $2,217.23$ & $3,673.71$ & 483.66 & 0.287 & 0.000 \\
\hline DMU O24 & 43.34 & 73.89 & $1,431.67$ & $2,000.00$ & $3,252.72$ & 78.04 & 0.721 & 0.066 \\
\hline UBT (Step 4) & 42.91 & 71.91 & $1,431.67$ & $2,013.81$ & $3,305.32$ & 62.61 & 0.545 & 0.000 \\
\hline MEFP O24 & 33.90 & 57.13 & $1,431.67$ & $1,500.00$ & $2,813.62$ & 50.36 & 0.434 & 0.000 \\
\hline DMU O26 & 41.79 & 49.60 & $1,093.36$ & $1,200.00$ & $2,425.56$ & 164.42 & 1.678 & 0.147 \\
\hline UBT (Step 3) & 39.38 & 47.80 & $1,093.36$ & $1,462.53$ & $2,593.18$ & 124.54 & 0.886 & 0.000 \\
\hline MEFP O26 & 35.97 & 52.46 & $1,093.36$ & $1,292.58$ & $2,424.56$ & 43.40 & 0.375 & 0.000 \\
\hline
\end{tabular}

Table 7. Summary of stepwise efficiency improvement path of the inefficient DMUs (cont.) 
a) Case $X Y$

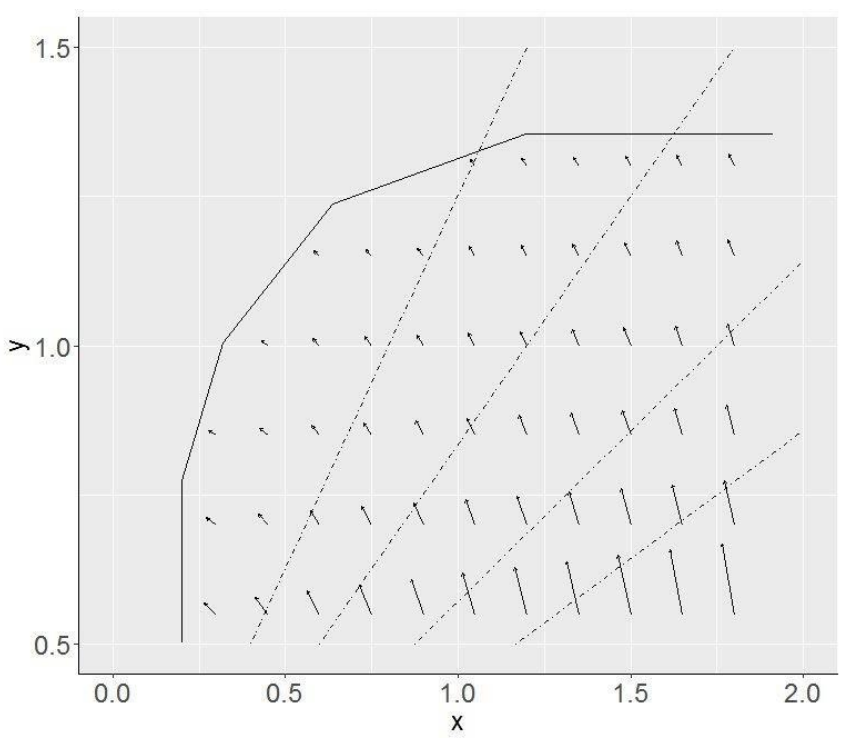

b) Case XX1

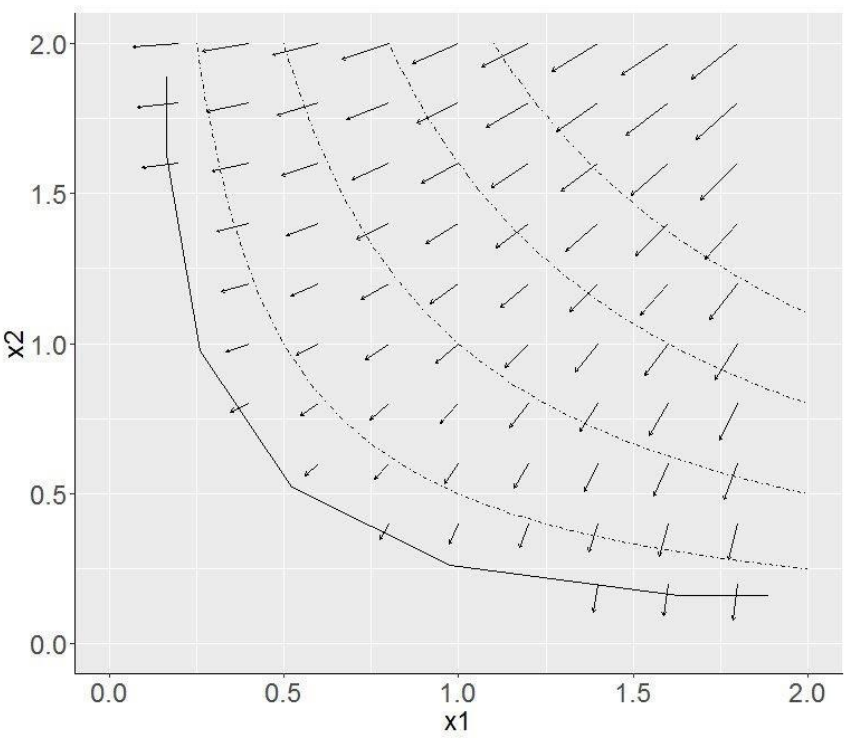

c) Case $1 Y Y$

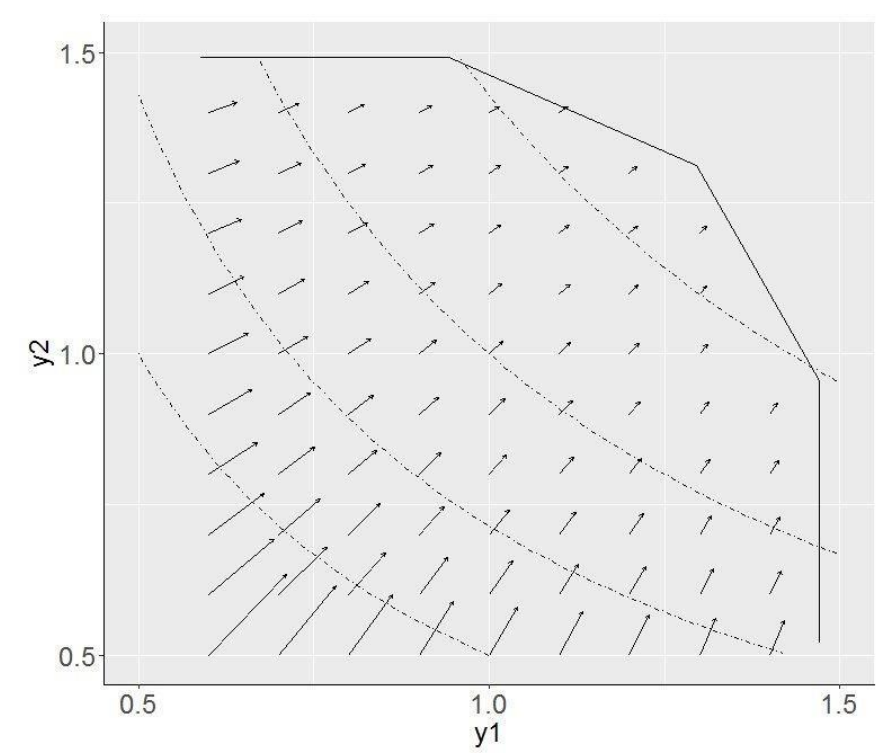

Figure 1. Efficiency vector fields for three bidimensional cases 


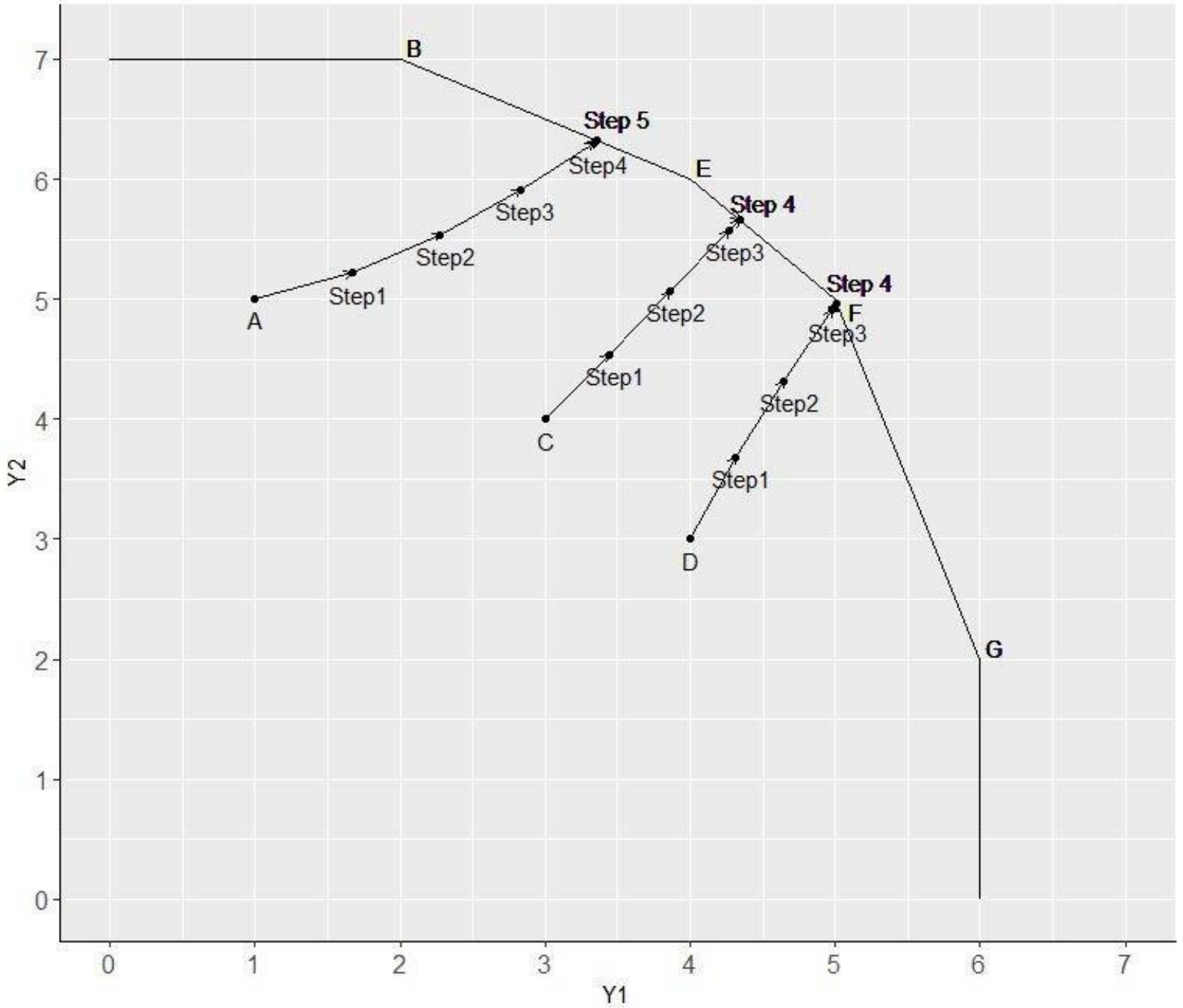

Figure 2. Gradient-based stepwise efficiency improvement paths for DMUs A, C and D $(\Delta=0.2)$ 


\section{SBI vs EFP}

$\diamond$ INEFFICENTDMUs $\quad$ EFFICIENTDMUs

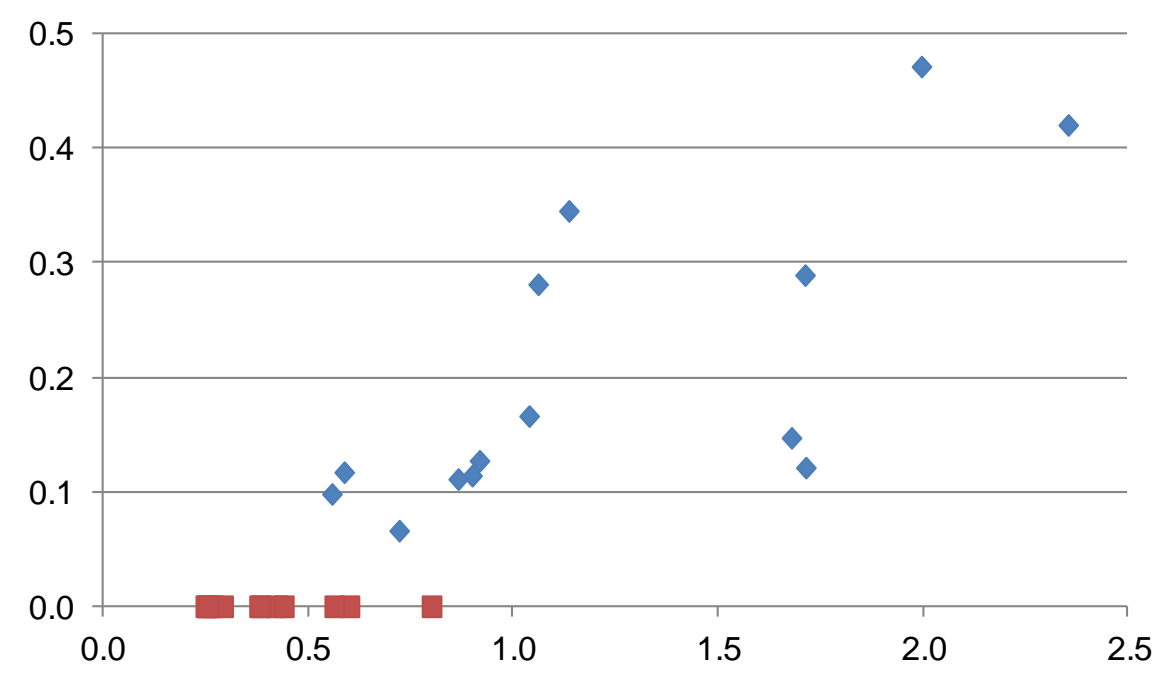

Figure 3. SBI and EFP of efficient and inefficient DMUs 
a)

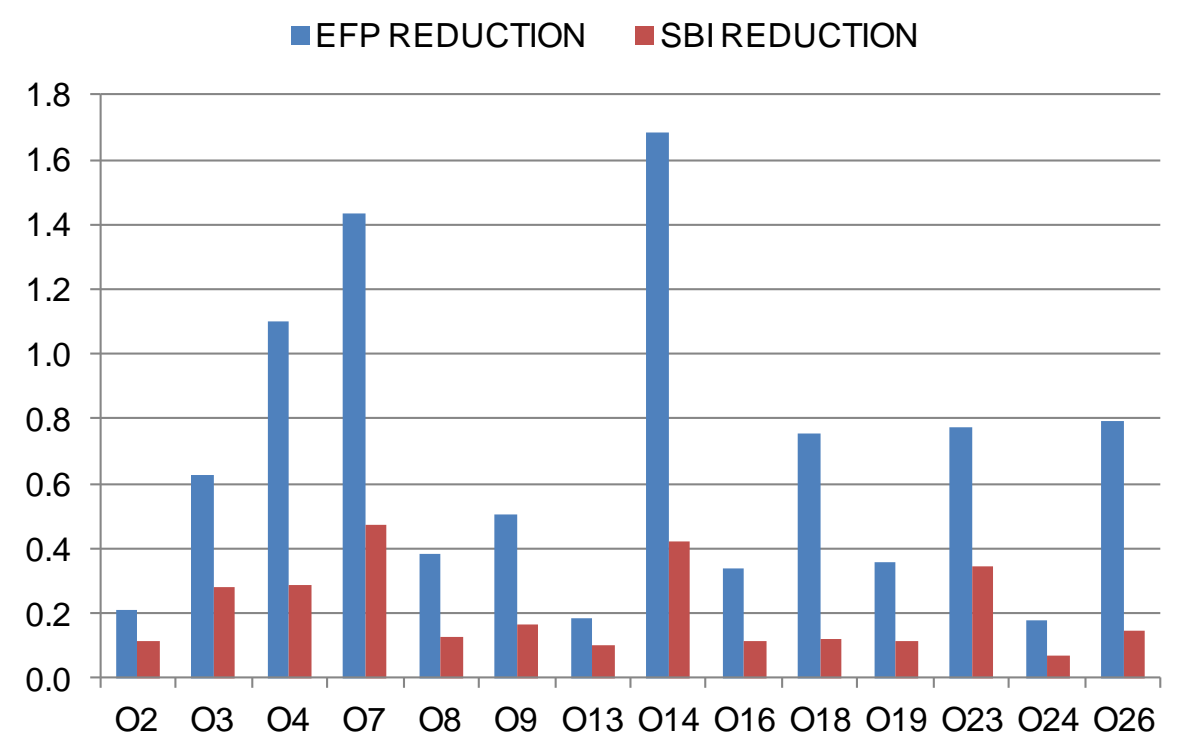

b)

SBI REDUCTION vs EFP REDUCTION

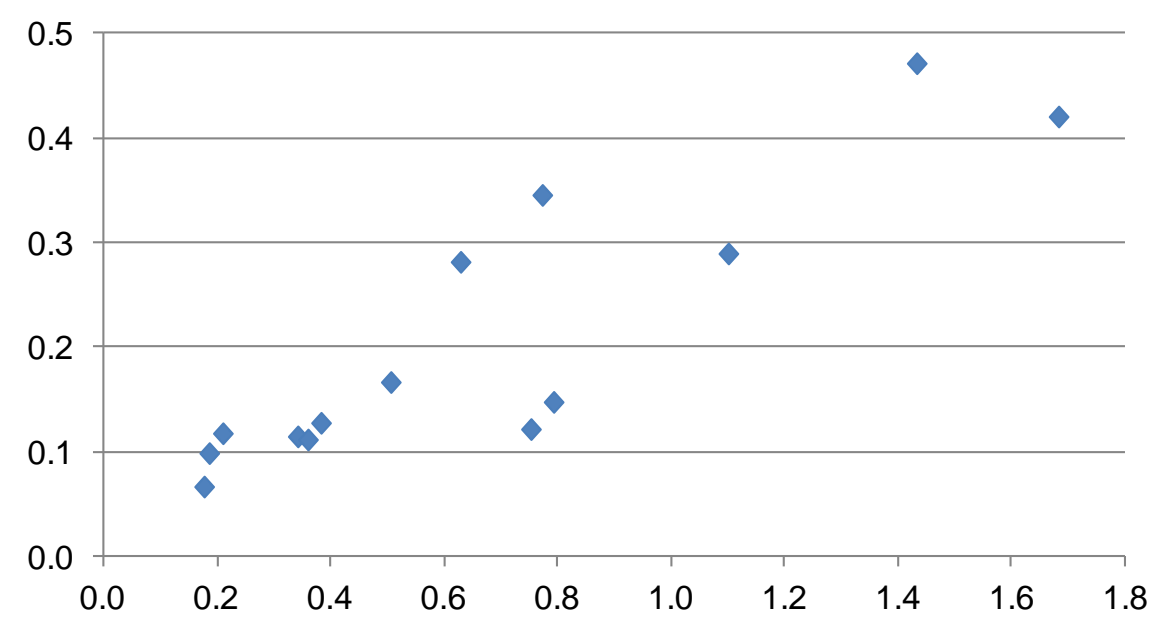

Figure 4. SBI and EFP reductions achieved along the different efficiency improvement paths 